\title{
Mechanistic insights into plasmonic photocatalysts in utilizing visible light
}

\author{
Kah Hon Leong ${ }^{1}$, Azrina Abd Aziz ${ }^{2}$, Lan Ching Sim ${ }^{1}$, Pichiah Saravanan ${ }^{*}$, Min Jang ${ }^{4}$ \\ and Detlef Bahnemann ${ }^{5}$
}

\author{
Review \\ Address: \\ ${ }^{1}$ Department of Environmental Engineering, Faculty of Engineering \\ and Green Technology, Universiti Tunku Abdul Rahman, Jalan \\ Universiti, Bandar Barat, 31900, Kampar, Perak, Malaysia, ${ }^{2}$ Faculty of \\ Engineering Technology, Universiti Malaysia Pahang, Lebuhraya Tun \\ Razak, Gambang, 26300 Kuantan, Pahang, Malaysia, ${ }^{3}$ Environmental \\ Nanotechnology Laboratory, Department of Environmental Science \\ and Engineering, Indian Institute of Technology (ISM) Dhanbad \\ 826004, Jharkhand, India, ${ }^{4}$ Department of Environmental \\ Engineering, Kwangwoon University, 447-1 Wolgye-Dong, \\ Nowon-Gu, Seoul, South Korea and ${ }^{5}$ Institut für Technische Chemie, \\ Leibniz Universität Hannover, Callinstrasse 3, 30167 Hannover, \\ Germany \\ Email: \\ Pichiah Saravanan* - pichiahsaravanan@gmail.com \\ * Corresponding author \\ Keywords: \\ localized surface plasmon resonance (LSPR); noble metal; plasmonic \\ photocatalyst; reactive radicals; Schottky junctions; visible light
}

Beilstein J. Nanotechnol. 2018, 9, 628-648. doi:10.3762/bjnano.9.59

Received: 28 September 2017

Accepted: 17 January 2018

Published: 19 February 2018

This article is part of the Thematic Series "Energy conversion, storage and environmental remediation using nanomaterials".

Guest Editor: W.-J. Ong

(C) 2018 Leong et al.; licensee Beilstein-Institut. License and terms: see end of document.

\begin{abstract}
The utilisation of sunlight as an abundant and renewable resource has motivated the development of sustainable photocatalysts that can collectively harvest visible light. However, the bottleneck in utilising the low energy photons has led to the discovery of plasmonic photocatalysts. The presence of noble metal on the plasmonic photocatalyst enables the harvesting of visible light through the unique characteristic features of the noble metal nanomaterials. Moreover, the formation of interfaces between noble metal particles and semiconductor materials further results in the formation of a Schottky junction. Thereby, the plasmonic characteristics have opened up a new direction in promoting an alternative path that can be of value to the society through sustainable development derived through energy available for all for diverse applications. We have comprehensively prepared this review to specifically focus on fundamental insights into plasmonic photocatalysts, various synthesis routes, together with their strengths and weaknesses, and the interaction of the plasmonic photocatalyst with pollutants as well as the role of active radical generation and identification. The review ends with a pinnacle insight into future perspectives regarding realistic applications of plasmonic photocatalysts.
\end{abstract}




\section{Review \\ Introduction}

Photocatalysts have played and will continue to play a pivotal role in environmental and energy applications in order to fulfil the needs of the current and future generation. They cleverly tackle the various limitations in the aforementioned field to satisfy the requirements of clean and green energy, and sustainable treatment of water and air. Indeed, years of research have been directed towards developing this sustainable process for a profound, promising and reliable approach towards energy generation and environmental remediation [1,2]. In line with this, the identification of photocatalysts capable of harvesting energy from the wider electromagnetic spectrum has become the focus of most researchers. The ability to harvest such a wide spectrum will lead to a pathway for better utilization of the solar spectrum. The invention and progression of plasmonic photocatalysts laid a foundation for the successful utilisation of longer wavelengths, known as "visible light photocatalysis".

The localised surface plasmon resonance (LSPR) is a unique characteristic of a plasmonic material, which can extend the absorption of light towards the visible light spectrum. Thus, LSPR greatly supports the utilisation of the solar spectrum, which comprises a considerable portion $(\approx 43 \%)$ of these wavelengths. The resonance appears when the photons interact with the metal nanoparticle surface conduction electrons [3]. This phenomenon enables these photocatalysts to concentrate the light energy surrounding it and leads to a strong improvement and activation of electron movement within the metal (i.e, noble metals) and semiconductor material [4].

Besides this, another distinguishing characteristic of plasmonic photocatalysts is that they also behave as an electron trap. The incorporation of a noble metal with semiconductors in the formation of Schottky junctions contributes to this behaviour [5]. This barrier formation prevents the recombination of electrons with the holes at the valance bands by trapping the electrons excited to the conduction bands. The LPSR, along with this distinctive characteristic feature, strengthens and contributes to the improvement of the plasmonic photocatalyst.

All these distinctive characteristics of plasmonic photocatalysts have motivated researchers in the field of light-driven nanomaterials, resulting in abundant findings on the successful application of this phenomenon through the support of noble metal. Hence, we deemed a comprehensive and timely review on this topic beneficial to its development, especially in the context of promoting sustainable photocatalysts. This review exclusively discusses the recent advances with regards to synthesis, the mechanism behind the plasmonic phenomenon, quantum efficiency, identification of active radicals and future perspectives.

\section{Fundamentals of plasmonic photocatalysts}

An amalgamation of noble and semiconductor metal forms an exclusive "plasmonic photocatalyst" classification. The term "plasmonic" is mainly in reference to the unique characteristics of LSPR and induced effects [6]. However, the formation of a Schottky junction does not classify as plasmonic or resonant effects. This formation is a result of notable contact between noble metal nanoparticles with a semiconductor. Plasmonic effects have been verified to increase the photocatalytic performance due to the intrinsic influences on the semiconductor photocatalyst. Plasmonic effects work to improve harvesting of visible light, prolong the lifetime of the charge carriers, improve activation of electron-hole pairs and enhance the redox reaction potential [7]. Moreover, the excitation of excess electrons and holes increases the rate of redox reaction through the heat generated. The distinct characteristic features of plasmonics are portrayed in Figure 1.

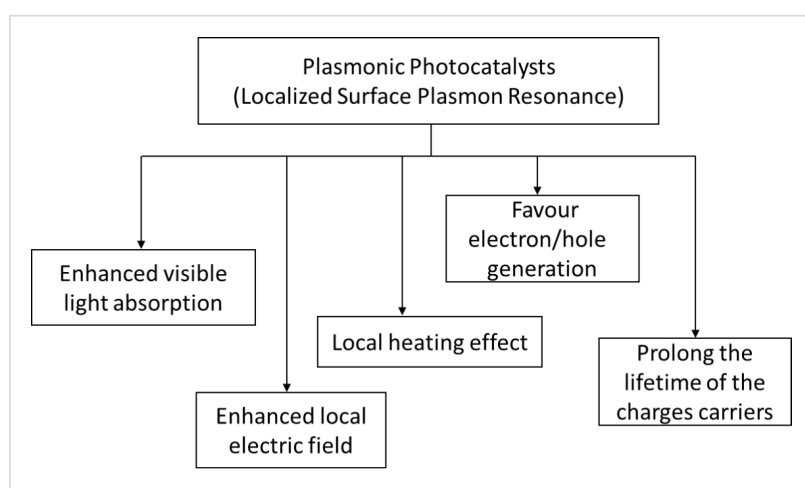

Figure 1: Distinctive features of plasmonics contributing to improved photocatalyst performance.

Noble metals such as $\mathrm{Au}, \mathrm{Ag}, \mathrm{Pt}, \mathrm{Pd}$ in the form of nanoparticles are a novel candidate for high absorption of visible light owing to their strong optical absorption in the entire solar region $[8,9]$. The unique characteristics of the LSPR effect in noble metal allow the enhanced absorption of photon energy from the visible light spectrum. Larger metallic nanoparticles $(>5 \mathrm{~nm})$ produce a robust surface plasmon emission in the visible spectrum [10]. The intensity of the plasmon band is highly dependent on the morphology, surrounding medium dielectric constant, and electronic interactions between the stabilizing ligands and nanoparticles [11]. Besides, the creation of a Schottky junction with a noble metal and a semiconductor acts to retard the recombination rate of electrons and holes [12].

LSPR takes place when noble metal NPs are excited by the oscillating electric field of the light. The photon frequency is designed to match with the natural frequency of the noble metal 
throughout the oscillation. This reduces the field on one side of the electron while increasing it on the other side of the noble metal. The development of this nonequilibrium condition results in the rearrangement of the charge density and builds an opposing electric field within the noble metal NPs. This further leads to the establishment of a coulombic restoring force and the noble metal NP electrons then experience harmonic oscillation $[1,5,13,14]$. These oscillating charges trigger the LSPR effects when the excited surface electric field frequency is sufficient, and the noble metal resonance leads to dynamic utilisation of visible light. A schematic representation of the phenomenon is illustrated in Figure 2. Hence, it is clear that absorption of photons emitted by the visible spectrum was promoted through LSPR and is very well ascribed to the electric polarization effect. Moreover, LSPR also speeds up the electron movement from the photoexcited noble metal to the semiconductor $[5]$.

The morphology, interparticle interactions and the local dielectric environment of noble metal nanoparticles is significantly influenced by the LSPR frequency [17-20]. It must be noted that not all noble metal nanoparticles of $10 \mathrm{~nm}$ diameter are able to utilize visible light, as shown in Figure 3. Ag and $\mathrm{Au}$ NPs are relatively good at harvesting visible light as compared to the others. These two noble metals can generate a stable, high electron-hole pair density [21]. However, the lower cost of Ag makes it more desirable to be utilized for broader applications as compared to $\mathrm{Au}$, and therefore, most studies utilize $\mathrm{Ag}$ as a plasmonic inducer [22-24]. Moving away from Au one can find that palladium $(\mathrm{Pd})$ in the form of NPs with a diameter of

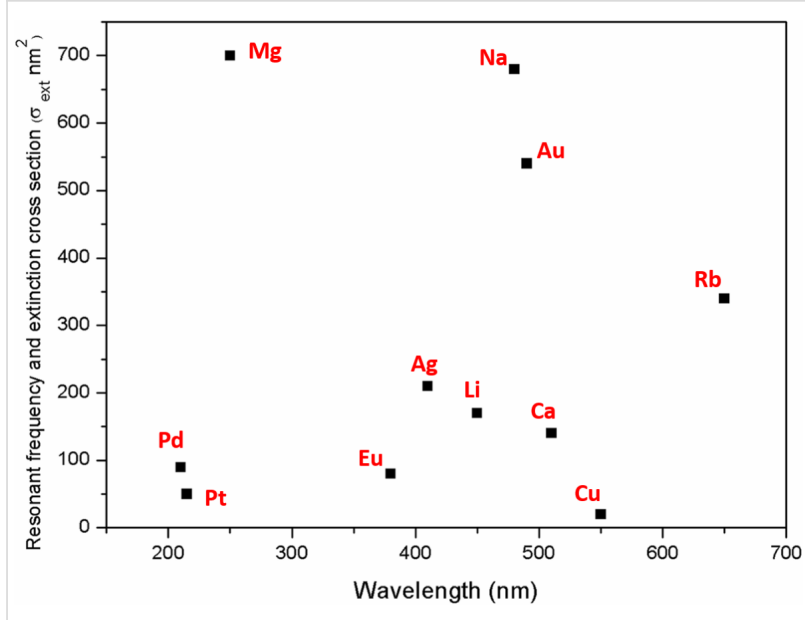

Figure 3: The metallic equivalent resonant wavelength for $10 \mathrm{~nm}$ diameter nanoparticles. Reprinted with permission from [27], copyright 2011 IOP Publishing.

$<10 \mathrm{~nm}$ is limited to the UV spectrum [25]. Nevertheless, the larger particle size and agglomeration of palladium particles contribute to the enhanced absorption of visible light. Mohapatra and coworkers demonstrated this where they successfully improved the harvesting potential of visible light for Pd NPs with a particle size in the range of $\approx 80 \mathrm{~nm}$ [25]. Similar results were also obtained by Kwak et al. where Pd NPs particles of $\approx 15 \mathrm{~nm}$ diameter were integrated onto $\mathrm{TiO}_{2}[26]$.

The plasmon-assisted physico-chemical interrelation between the noble metal and semiconductor is the key for understanding electron generation and excitation. Once sufficient photon
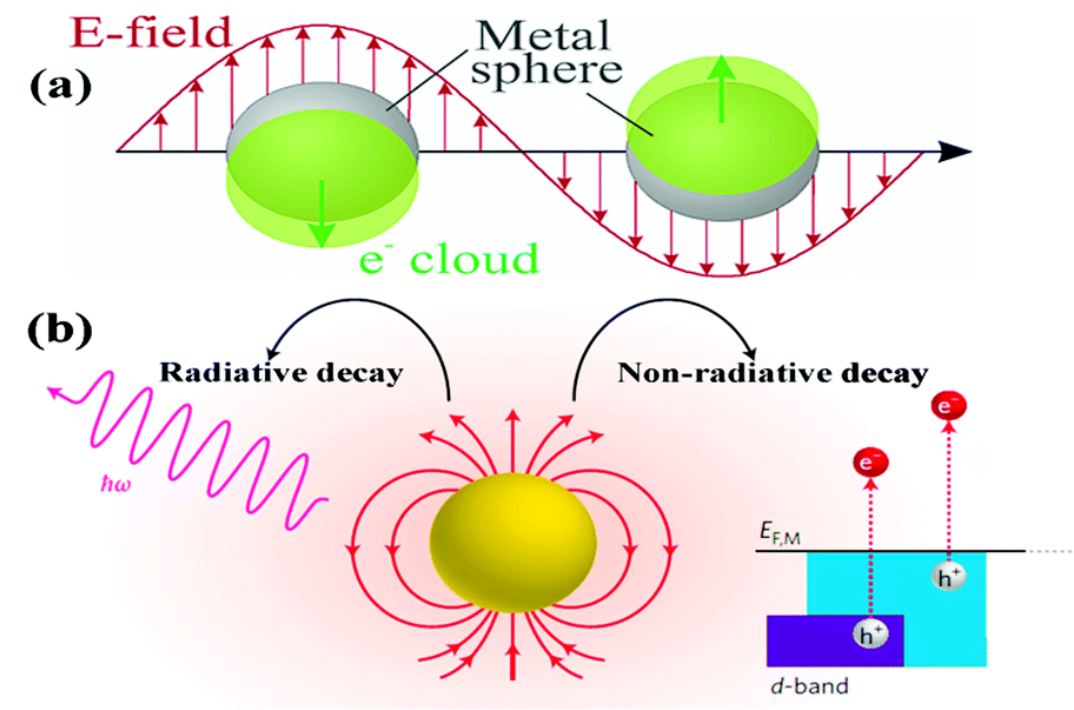

Figure 2: (a) Representation of localized surface plasmon resonance (LSPR) evolution in a noble metal particle irradiated by a light source. Reprinted with permission from [15], copyright 2003 American Chemical Society. (b) LSPR decay processes. Reprinted with permission from [16], copyright 2014 Nature Publishing Group. 
energy is obtained, it will excite the free electrons present in the noble metal to a higher Fermi level $[28,29]$. This movement of electrons leads to the redistribution of energy through non-equilibrium Fermi-Dirac statistics. During this redistribution, the excited electrons are transferred from the noble metal to the semiconductor and the phenomenon leads to the formation of a Schottky junction. The formed Schottky junction enables electron movement towards the semiconductor through the LSPR decay effect as illustrated in Figure 4 and Figure 5 [30], leaving behind positively charged holes at the valence band or their transfer to the counter electrode preventing recombination [16,31-35]. Figure 4a demonstrates the excited electron mobility from the thermal equilibrium to the upper energy state. Meanwhile Figure 4b illustrates the redistribution of the Fermi-Dirac distribution in a metal nanoparticle achieved through the collision. Figure $4 \mathrm{c}$ demonstrates the movement of excited electrons to the ordinary distribution and different regions $[3,6]$.

Moreover, noble metals offer a rapid path for charge movement through the interface as electron-hole trap centres and allow more energetic spots for photoreactions to occur. Thus the combined traits act to readily suppress the electron-hole recombination.

\section{Synthesis routes for plasmonic photocatalysts}

There are quite a number of ways to synthesize plasmonic photocatalysts. The most important step in their fabrication is the incorporation or deposition of noble metals onto the surface of a semiconductor. The most commonly studied semiconductor is $\mathrm{TiO}_{2}$, which exhibits superior photocatalysis efficiency.

Such materials have already been applied in various environmental and energy conversion applications [36]. Recently, the evolution of a metal-free semiconductor, graphitic carbon nitride $\left(\mathrm{g}-\mathrm{C}_{3} \mathrm{~N}_{4}\right)$, has been discovered as an alternative for plas-

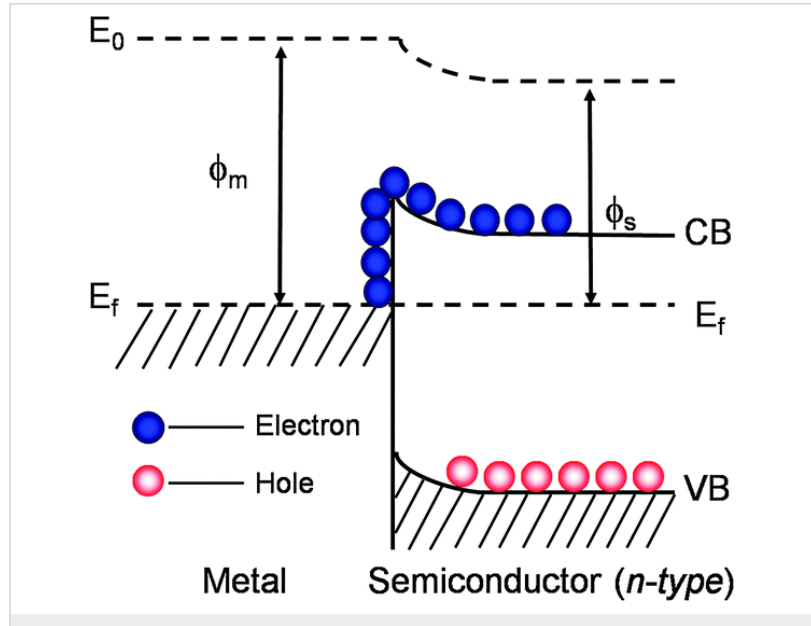

Figure 5: Schematic of the Schottky junction mechanism. Reprinted with permission from [35], copyright 2014 Royal Society of Chemistry.

monic photocatalysts. This metal-free semiconductor by itself has the ability to extend the absorption of visible light [37-44]. Moreover, future studies on other semiconductors such as metal chalcogenides and metal phosphides could lead to further developments for plasmonic photocatalysts to address current environmental and energy issues [45-49].

Synthesis routes such as sol-gel, hydrothermal, microwave hydrothermal, impregnation, electrochemical deposition, chemical deposition, deposition-precipitation, UV photodeposition and direct sunlight photodeposition have been reported [23,5086]. The conventional and most frequently used methods are the sol-gel and deposition-precipitation methods. These are mostly widely preferred due to the relatively facile and direct synthesis for obtaining the target composite. However, the deposition concentration of noble metal is moderately low [3]. Meanwhile, the hydrothermal method often suffers from major metal nanoparticle aggregation issues [3]. Similarly, chemical methods result in aggregation of nanoparticles throughout the adsorption stage and thus decrease the efficiency during photocatalysis [3].

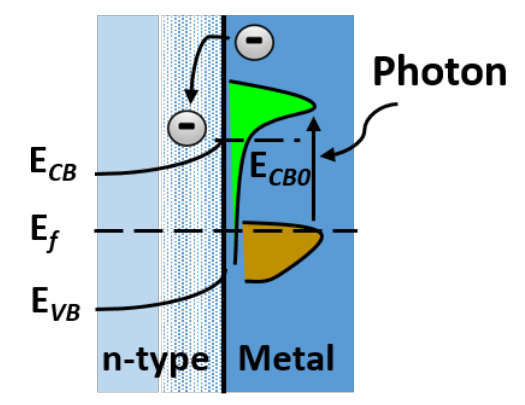

(a)

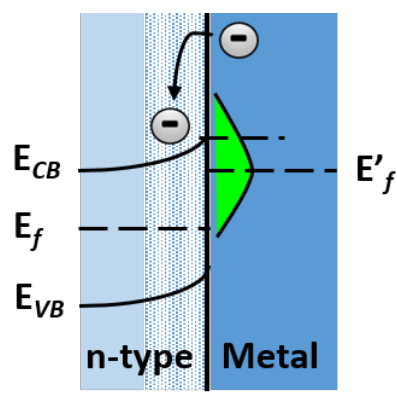

(b)

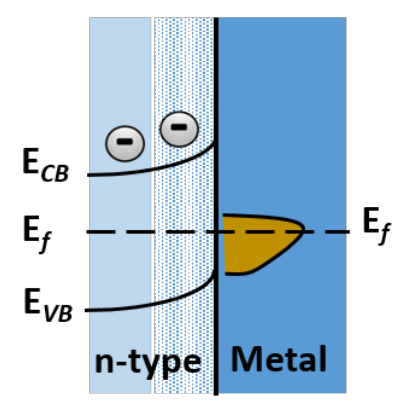

(c)

Figure 4: Pictorial representation of the localized surface plasmon resonance principle. Reprinted with permission from [31], copyright 2016 Springer. 
The photodeposition method has overcome these disadvantages and produces a higher concentration of incorporated noble metal into the semiconductor composite [1]. This method is assisted by light whereby the deposition of noble metal nanoparticles takes place on the semiconductor surface. The most common light source used is a UV lamp producing a highenergy spectrum. Since most contemporary research promotes sustainable and green synthesis routes, replacing the UV lamp as the source of photons with renewable energy could be an alternative. Moreover, researchers have proven the possibility of using direct sunlight as an alternative to artificial UV light for such noble metal deposition. In a study by Leong and co-workers, they successfully achieved the deposition of $\mathrm{Ag}$ and $\mathrm{Pd}$ onto the surface of $\mathrm{TiO}_{2}$ via this renewable route. They also used sunlight to synthesize the LPSR-induced photocatalyst through the electron formation and mobility mechanism. Thus, the fabricated photocatalyst exhibited pronounced efficiency in generating reactive oxygen species [50,51]. In general, this specific deposition mechanism functions similar to that of $\mathrm{TiO}_{2}$ which has a distinctive electronic configuration structure (filled valence band and an empty conduction band). When exposed to direct sunlight irradiation, the UV light breaks the band gap energy of $\mathrm{TiO}_{2}(3.2 \mathrm{eV})$ and then activates the electrons in the valence band. Thus, activated electrons move to the conduction band, leaving behind enriched holes in the valance band. The free electrons in the conduction band are then free to react with specific precursors through the support of reducing agents, resulting uniform metallic nanoparticles deposited on the surface. The holes then react with ethylene glycol to form aldehyde. Table 1 comprehensively presents the various synthesis routes for fabrication of LPSR-induced photocatalysts. Interestingly, the fabrication of plasmonic photocatalysts using sustainable approaches showed better performance as compared to the conventional synthesis methods. The mecha- nism of nanoparticle formation and deposition using an sustainable approach is illustrated in Figure 6.

\section{Interaction of noble metals with semiconductor materials}

Most of the literature claims that the incorporation of plasmonic nanoparticles with semiconductors can extend light absorption towards the visible and near infrared (NIR) spectrum. But in order to show enhanced plasmonic photocatalysis performance, the understanding of the material system plays a vital role. This includes the type of noble metal and semiconductor photocatalyst together with their morphology, porosity, crystallinity, contact form, etc. Although many semiconductor metal oxides such as $\mathrm{N}$-doped $\mathrm{TiO}_{2}$ [88], $\mathrm{Fe}_{2} \mathrm{O}_{3}$ [89], CdS [90] and $\mathrm{Bi}_{2} \mathrm{O}_{3}[91,92]$ have been reported, this section will mainly focus on $\mathrm{TiO}_{2}$, which is the most widely studied. $\mathrm{Au}$ or $\mathrm{Ag}$ nanoparticles can be employed to produce an outstanding plasmonic effect in the visible and UV range [93-96]. Additionally, other noble metals such as Pt and Pd also exhibited a similar photocatalytic performance $[97,98]$.

\section{$\mathrm{Ag}, \mathrm{Au}, \mathrm{Pt}$ and $\mathrm{Pd}$ nanoparticles}

$\mathrm{Ag}$ and $\mathrm{Au}$ are the most preferred noble metals for interaction with various types of semiconductors due to the strong LSPR produced; however, this phenomenon is mainly affected by morphology, size, and composition of the NPs as well as the dielectric properties of the surrounding medium $[99,100]$. Xu et al. reported that the content of metallic Ag and the extent of metallic Ag dispersion were factors which can be controlled to improve photocatalytic efficiency [101]. The LSPR of Ag in a $\mathrm{Ag} / \mathrm{AgCl}$ composite was found to enhance the local inner electromagnetic field and prolong the lifetime of the charge carriers. Wang et al. observed that $\mathrm{Ag} @ \mathrm{AgBr}$ exhibited enhanced photocatalytic activity as compared to $\mathrm{Ag} / \mathrm{AgCl}$ by a factor of 1.5 .

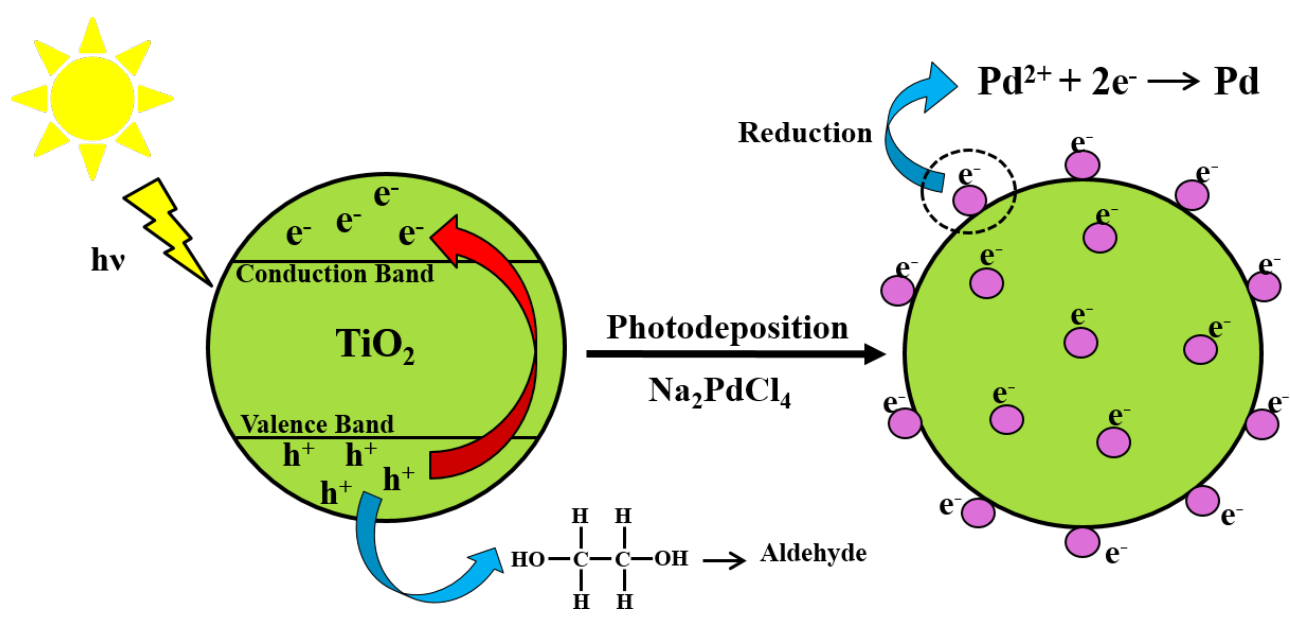

Figure 6: Synthesis of $\mathrm{Pd} / \mathrm{TiO}_{2}$ photocatalyst via sunlight-assisted photodeposition [50]. 
Table 1: Summary of various synthesis routes for preparation of plasmonic photocatalysts.

\begin{tabular}{|c|c|c|}
\hline $\begin{array}{l}\text { Plasmonic } \\
\text { photocatalyst }\end{array}$ & Preparation method & Light source \\
\hline $\mathrm{Ag}-\mathrm{TiO}_{2}$ & UV photodeposition & $\begin{array}{l}\text { visible light }(457 \mathrm{~nm}) \\
\text { and sunlight }\end{array}$ \\
\hline $\mathrm{Ag}-\mathrm{TiO}_{2}$ & wet chemical & sunlight \\
\hline $\mathrm{Ag}-\mathrm{TiO}_{2}$ & ultrasound & $\begin{array}{l}\text { visible light } \\
(400-700 \mathrm{~nm})\end{array}$ \\
\hline $\mathrm{Ag}-\mathrm{TiO}_{2}$ & sol-gel process & $\begin{array}{l}\text { visible light } \\
\text { (18 W fluorescence } \\
\text { TL-D tube light) }\end{array}$ \\
\hline $\mathrm{Ag}-\mathrm{TiO}_{2}$ & hydrothermal & $\begin{array}{l}\text { visible light } \\
(400-500 \mathrm{~nm})\end{array}$ \\
\hline $\mathrm{Ag}-\mathrm{TiO}_{2}$ & $\begin{array}{l}\text { electrochemical } \\
\text { deposition }\end{array}$ & $\begin{array}{l}\text { visible light } \\
\text { (>420 nm) }\end{array}$ \\
\hline $\mathrm{Ag}-\mathrm{TiO}_{2}$ & electrodeposition & $\begin{array}{l}\text { visible light } \\
(400-700 \mathrm{~nm})\end{array}$ \\
\hline $\mathrm{Ag}-\mathrm{TiO}_{2}$ & sulfydryl-assisted & $\begin{array}{l}\text { visible light } \\
\text { (>400 nm) }\end{array}$ \\
\hline $\mathrm{Ag}-\mathrm{TiO}_{2}$ & photodeposition & $\begin{array}{l}\text { visible light } \\
\text { ( } 200 \mathrm{~W} \text { halogen } \\
\text { lamp) }\end{array}$ \\
\hline $\mathrm{Ag}-\mathrm{TiO}_{2}$ & $\begin{array}{l}\text { photoreduction by } \\
\text { artificial UV light }\end{array}$ & $\begin{array}{l}\text { visible light } \\
\text { (>400 nm) }\end{array}$ \\
\hline $\mathrm{Ag}-\mathrm{C}_{3} \mathrm{~N}_{4}$ & reflux treatment & $\begin{array}{l}\text { visible light } \\
\text { (>420 nm) }\end{array}$ \\
\hline
\end{tabular}

\begin{tabular}{|c|c|c|}
\hline $\mathrm{Ag}-\mathrm{TiO}_{2}$ & $\begin{array}{l}\text { photoreduction by direct } \\
\text { sunlight }\end{array}$ & $\begin{array}{l}\text { visible light } \\
\text { (>420 nm) }\end{array}$ \\
\hline $\mathrm{Ag}-\mathrm{TiO}_{2}$ & $\begin{array}{l}\text { photochemical reduction } \\
\text { under Xe lamp }\end{array}$ & $\begin{array}{l}\text { visible light } \\
\text { (>400 nm) }\end{array}$ \\
\hline $\mathrm{Au}-\mathrm{TiO}_{2}$ & impregnation & $\begin{array}{l}\text { visible light } \\
(460-700 \mathrm{~nm})\end{array}$ \\
\hline $\mathrm{Au}-\mathrm{TiO}_{2}$ & impregnation & $\begin{array}{l}\text { visible light } \\
\text { (LED green light) }\end{array}$ \\
\hline $\mathrm{Au}-\mathrm{TiO}_{2}$ & sol-gel & $\begin{array}{l}\text { UV light } \\
\text { (200 W Hg lamp) }\end{array}$ \\
\hline $\mathrm{Au}-\mathrm{TiO}_{2}$ & deposition-precipitation & $\begin{array}{l}\text { visible light } \\
\text { (>420 nm) }\end{array}$ \\
\hline $\mathrm{Au}-\mathrm{TiO}_{2}$ & deposition-precipitation & $\begin{array}{l}\text { visible light } \\
(400-700 \mathrm{~nm})\end{array}$ \\
\hline $\mathrm{Au}-\mathrm{TiO}_{2}$ & deposition-precipitation & sunlight \\
\hline $\mathrm{Au}-\mathrm{TiO}_{2}$ & deposition-precipitation & $\begin{array}{l}\text { simulated solar light } \\
\text { (Abet Technologies, } \\
\text { Sun 2000) }\end{array}$ \\
\hline $\mathrm{Au}-\mathrm{TiO}_{2}$ & deposition-precipitation & sunlight \\
\hline
\end{tabular}

Photocatalysis performance

Ref.

enhanced $\mathrm{H}_{2}$ production of $90 \mu \mathrm{mol}$ (artificial visible light) and $105 \mu \mathrm{mol}$ (sunlight) as compared to $\mathrm{TiO}_{2}(70 \mu \mathrm{mol}$, artificial visible light and $80 \mu \mathrm{mol}$, sunlight)

increase in Ag NP loading increased the photocatalysis efficiency: $97 \%$ degradation for $10 \mu \mathrm{M}$ MB in 60 min and $93 \%$ for $5 \mu \mathrm{M} \mathrm{MO}$ in $40 \mathrm{~min}$

$20 \mathrm{wt} \% \mathrm{Ag}-\mathrm{TiO}_{2}$ showed acetone degradation rate of $0.57 \mathrm{mg} \mathrm{m}^{-3} \mathrm{~min}^{-1}$ as compared to almost $0 \mathrm{mg} \mathrm{m}^{-3} \mathrm{~min}^{-1}$ for $\mathrm{TiO}_{2}$

complete removal of indigo carmine $\left(2.5 \times 10^{-5} \mathrm{M}\right)$ was achieved in $3 \mathrm{~h}$

complete removal of rhodamine $\mathrm{B}(2 \mathrm{mg} / \mathrm{L})$ in $180 \mathrm{~min}$ by $\mathrm{Ag}-\mathrm{TiO}_{2}$ arrays; $55 \%$ for $\mathrm{TiO}_{2}$

photocatalysis of $\mathrm{Ag}-\mathrm{TiO}_{2}$ achieved about $80 \%$ removal of methyl blue $\left(2 \times 10^{-5} \mathrm{M}\right)$ in $2.5 \mathrm{~h}$ against $\mathrm{TiO}_{2}$

complete decomposition of methyl blue with $\mathrm{Ag} / \mathrm{TiO}_{2}$ core-shell nanowires within 40 min and 10 min for UV and visible light, respectively

almost complete degradation (98\%) of methyl orange was [59] achieved by $\mathrm{Ag} / \mathrm{TiO}$ as compare to $\mathrm{TiO}_{2}(30 \%)$

$\mathrm{TiO}_{2}$ with $2 \% \mathrm{Ag}$ obtained improved photodegradation of rhodamine $B\left(10^{-5} \mathrm{M}\right)$ with $\approx 30 \%$ improvement under visible light irradiation

complete degradation of rhodamine $B$ was achieved for $\mathrm{TiO}_{2}$ with $1 \mathrm{wt} \% \mathrm{Ag}$ with initial dye concentration of $10 \mathrm{mg} \mathrm{L}^{-1}$ in $30 \mathrm{~min}$

enhanced photocurrent intensity (a factor of 4 ), photodegradation of methylene blue (by 1.8 times) and hydrogen production (by 30 times) as compared with $\mathrm{C}_{3} \mathrm{~N}_{4}$

0.3 wt $\% \mathrm{Ag} / \mathrm{TiO}_{2}$ showed clear photodegradation of amoxicillin and 2,4-dichlorophenol in contrast to $\mathrm{TiO}_{2}$ incorporation of $\mathrm{Ag}$ onto $\mathrm{TiO}_{2}$ resulted in significant photodegradation of rhodamine $\mathrm{B}$ as compared to $\mathrm{TiO}_{2}$ (by a factor of more than 2)

complete decolourization of methylene blue $\left(1.0 \times 10^{-5} \mathrm{M}\right)$ [64] in a short duration (10 $\mathrm{min}$ ); complete degradation was reported for rhodamine $\mathrm{B}(2 \mathrm{~min})$ and $\approx 25 \%$ degradation of 4-chlorophenol in 180 min

significant enhancement was achieved with complete conversion of formaldehyde of $83.3 \%$ under visible light at $44 \%$ relative humidity

Au deposition over $\mathrm{TiO}_{2}$ enhanced the conversion of $\mathrm{CO}_{2}$ to $\mathrm{CO}$ with a rate of $4144 \mu \mathrm{mol} \mathrm{g} \mathrm{g}^{-1} \mathrm{~h}^{-1}$ which is 345 -fold higher than pure $\mathrm{TiO}_{2}$

the presence of Au enhanced the photocatalytic activity of both methylene orange removal and hydrogen production improved charge separation and transfer resulted to an enhanced $\mathrm{H}_{2}$ evolution rate

highest degradation efficiency of $97 \%$ in 50 min was reported for Safranin $\mathrm{O}$ dye after the incorporation of $\mathrm{Au}$ nanoparticles

$\mathrm{H}_{2}$ production increased up to $5-6 \mathrm{mmol}\left(\mathrm{g}^{-1} \mathrm{~h}^{-1}\right)$ under simulated solar irradiation and further increased with increased Au concentration

mesoporous $\mathrm{Au} / \mathrm{TiO}_{2}$ with 4 wt \% Au resulted in $99 \%$ removal of alizarin as compared to P25 (65\%) in $80 \mathrm{~min}$
[52] 
Table 1: Summary of various synthesis routes for preparation of plasmonic photocatalysts. (continued)

\begin{tabular}{|c|c|c|c|c|}
\hline $\mathrm{Au}-\mathrm{TiO}_{2}$ & $\begin{array}{l}\text { chemical precipitation } \\
\text { method }\end{array}$ & $\begin{array}{l}\text { visible light } \\
(>305 \mathrm{~nm})\end{array}$ & $\begin{array}{l}\text { the surface deposition approach significantly improved the } \\
\text { photoactivity by } 5-10 \text {-fold for the studied micropollutant }\end{array}$ & [72] \\
\hline $\mathrm{Au}-\mathrm{TiO}_{2}$ & $\begin{array}{l}\text { microwave-chemical } \\
\text { reduction }\end{array}$ & $\begin{array}{l}\text { visible light } \\
(>420 \mathrm{~nm})\end{array}$ & $\begin{array}{l}\mathrm{H}_{2} \text { production rate for } \mathrm{Au} / \mathrm{TiO}_{2} \text { reached } 4.3 \mu \mathrm{mol} \mathrm{cm} \mathrm{cm}^{-2} \mathrm{~h}^{-1} \\
\text { as compared to } 0.47 \mu \mathrm{mol} \mathrm{cm} \mathrm{cm}^{-2} \mathrm{~h}^{-1} \text { for } \mathrm{TiO}_{2}\end{array}$ & [73] \\
\hline $\mathrm{Pd}-\mathrm{TiO}_{2}$ & impregnation & $\begin{array}{l}\text { UV and visible light } \\
(400-700 \mathrm{~nm})\end{array}$ & $\begin{array}{l}\mathrm{Pd} \text { activates SPR which escalates hydrogen production } \\
\text { (by a factor of } 4 \text { ); the reaction requires the presence of } \\
\text { both UV and visible light to achieve } 800 \mu \mathrm{mol} / \mathrm{g}\end{array}$ & [74] \\
\hline $\mathrm{Pd}-\mathrm{TiO}_{2}$ & sol-gel & $\begin{array}{l}\text { UV light } \\
\text { (8 W UV lamp) }\end{array}$ & $\begin{array}{l}\text { Pd-doped } \mathrm{TiO}_{2} \text { enhanced the degradation of } \mathrm{NO}_{x}(88 \%) \\
\text { and } \mathrm{CO}(74 \%) \text { as compared to un-doped } \mathrm{TiO}_{2}(59 \% \text { and } \\
56 \%)\end{array}$ & [75] \\
\hline $\mathrm{Pd}-\mathrm{TiO}_{2}$ & hydrothermal & $\begin{array}{l}\text { visible light } \\
(>400 \mathrm{~nm})\end{array}$ & $\begin{array}{l}\text { optimal photocatalytic performance of } \mathrm{p} \text {-nitrophenol } \\
\text { reduction was achieved by loading } 1.0 \mathrm{~mol} \% \mathrm{Pd} \text { onto } \\
\text { titania nanotubes; a rate constant of } 0.7072 \mathrm{~min}^{-1} \text { was } \\
\text { reported for the photocatalytic oxidation }\end{array}$ & [76] \\
\hline $\mathrm{Pd}-\mathrm{TiO}_{2}$ & glucose reduction & $\begin{array}{l}\text { UV light } \\
\text { (150 W Hg lamp) }\end{array}$ & $\begin{array}{l}\mathrm{Pd} \mathrm{NPs} \text { on the } \mathrm{TiO}_{2} \text { surface substantially increase the } \\
\text { electron movement and act as vital sites for adsorption to } \\
\text { promote } \mathrm{CO}_{2} \text { hydrogenation; as a result, } 1.0 \mathrm{wt} \% \mathrm{Pd} \\
\text { loading yielded } 355.62,46.35 \text {, and } 39.69 \mu \mathrm{mol} / \mathrm{g} \text { for } \mathrm{CH}_{4} \text {, } \\
\mathrm{CO} \text { and } \mathrm{C}_{2} \mathrm{H}_{6} \text {, respectively }\end{array}$ & [77] \\
\hline $\mathrm{Pd}-\mathrm{TiO}_{2}$ & reduction & $\begin{array}{l}\text { UV light } \\
\text { (100 W UV lamp) }\end{array}$ & 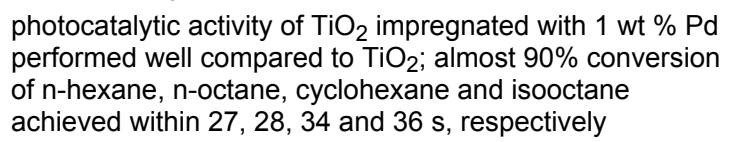 & [78] \\
\hline $\mathrm{Pd}-\mathrm{TiO}_{2}$ & chemical reduction & $\begin{array}{l}\text { solar stimulator } \\
\left(50 \mathrm{~mW} \mathrm{~cm}^{-2}\right. \\
300 \mathrm{~W} \text { Xe lamp) }\end{array}$ & $\begin{array}{l}\text { immense improvement in photocatalytic activity with } \\
\text { enhanced } \mathrm{H}_{2} \text { production as compared to } \mathrm{TiO}_{2} ; \mathrm{TiO}_{2} \\
\text { decorated with } 0.18 \mathrm{wt} \% \mathrm{Pd} \mathrm{NPs} \text { showed an } \mathrm{H}_{2} \\
\text { production rate of } 3096 \mu \mathrm{mol} \mathrm{g}^{-1} \mathrm{~h}^{-1}\end{array}$ & [79] \\
\hline $\mathrm{Pd}-\mathrm{TiO}_{2}$ & $\begin{array}{l}\text { chemical } \\
\text { photodeposition }\end{array}$ & solar simulator & higher decolourization (32\%) for rhodamine B & [80] \\
\hline $\mathrm{Pd}-\mathrm{TiO}_{2}$ & solar deposition & sunlight & $\begin{array}{l}\text { complete degradation ( } 97.5 \% \text { ) of amoxicillin was obtained } \\
\text { within } 5 \mathrm{~h} \text { by optimum loading of } 0.5 \mathrm{wt} \% \mathrm{Pd} \text { onto the } \\
\text { surface of } \mathrm{TiO}_{2}\end{array}$ & [50] \\
\hline $\begin{array}{l}\text { Pt-loaded } \\
\mathrm{g}-\mathrm{C}_{3} \mathrm{~N}_{4}\end{array}$ & polyol & $\begin{array}{l}15 \text { W energy saving } \\
\text { daylight }\end{array}$ & $\begin{array}{l}2 \text { wt \% Pt on } \mathrm{g}_{-} \mathrm{C}_{3} \mathrm{~N}_{4} \text { showed highest } \mathrm{CH}_{4} \text { yield of } \\
13.02 \mu \mathrm{mol} \mathrm{g}^{-1} \text { as compared to unloaded g- } \mathrm{C}_{3} \mathrm{~N}_{4} \\
\left(2.55 \mu \mathrm{mol} \mathrm{g}{ }^{-1}\right) \text { after } 10 \mathrm{~h} \text { of irradiation }\end{array}$ & [81] \\
\hline $\mathrm{Pt}-\mathrm{TiO}_{2}$ & sol-gel & $18 \mathrm{~W}$ daylight lamp & $\begin{array}{l}\text { better formaldehyde degradation (98.3\%) as compared to } \\
\mathrm{TiO}_{2}(75.2 \%)\end{array}$ & [82] \\
\hline $\mathrm{Pt}-\mathrm{TiO}_{2}$ & impregnation-reduction & $\begin{array}{l}\text { visible light } \\
(>450 \mathrm{~nm})\end{array}$ & $\begin{array}{l}\text { improved catalytic performance of aniline oxidation was } \\
\text { achieved for } 2 \mathrm{wt} \% \mathrm{Pt} \text { particles with } 12 \mathrm{~h} \text { of photoreaction }\end{array}$ & [83] \\
\hline $\mathrm{Pt}-\mathrm{TiO}_{2}$ & impregnation-reduction & $\begin{array}{l}\text { UV light }(350 \mathrm{~W} \\
\text { high-pressure } \mathrm{Hg})\end{array}$ & $\begin{array}{l}\text { optimal } \mathrm{Pt} \text { loading of } 1.2 \mathrm{wt} \% \text { exhibited increased } \\
(125 \text {-fold }) \mathrm{H}_{2} \text { production rate compared to unmodified } \\
\mathrm{TiO}_{2} \text { microspheres }\end{array}$ & [84] \\
\hline $\mathrm{Pt}-\mathrm{TiO}_{2}$ & chemical deposition & $\begin{array}{l}\text { visible light } \\
(>420 \mathrm{~nm})\end{array}$ & $\begin{array}{l}\text { rate constant of } \mathrm{Pt}-\mathrm{TiO}_{2} \text { for } 10 \mathrm{mg} / \mathrm{L} \text { nitrobenzene } \\
\text { degradation was } 2 \times \text { larger than with } \mathrm{TiO}_{2}\end{array}$ & [85] \\
\hline $\mathrm{Pt}-\mathrm{TiO}_{2}$ & $\begin{array}{l}\text { UV-assisted } \\
\text { photodeposition }\end{array}$ & $\begin{array}{l}\text { visible light } \\
(>420 \mathrm{~nm})\end{array}$ & $\begin{array}{l}\left.3 \mathrm{mM} \mathrm{H}_{2} \mathrm{PtCl}_{6} \text { yielded highest photodegradation ( } 84.27 \%\right) \\
\text { for methyl orange }\end{array}$ & [86] \\
\hline $\mathrm{AgCl}-\mathrm{CN}$ & deposition-precipitation & $\begin{array}{l}15 \text { W energy saving } \\
\text { daylight }\end{array}$ & $\begin{array}{l}\text { 2.5-fold increase in methane yield of was achieved for the } \\
\mathrm{AgCl}-\mathrm{CN} \text { compared to } \mathrm{CN}\end{array}$ & [87] \\
\hline
\end{tabular}

This achievement was attributed to the lower electron affinity of $\mathrm{Br}^{-}$compared to $\mathrm{Cl}^{-}$. The variation in shape and diameter of the Ag NPs resulted in an increased frequency range of plasmonic oscillation and thus $\mathrm{Ag} @ \mathrm{AgBr}$ was found to readily absorb a wide range of the visible spectrum [102]. Purbia et al. incorporated $\mathrm{Au}$ as a secondary noble metal in a $\mathrm{Ag} @ \mathrm{AgBr}$ heterostructure in which the LSPR of Au NPs remained in the visible region. The resulting bimetallic $(\mathrm{Ag}-\mathrm{Au})$ coupling boosted the photocatalytic efficiency by 16 -fold as compared to mono-metallic (AgBr). The increase of the resonance- excited hot-electron density on the surface of Ag and Au NPs escalated the Fermi energy level of Ag and Au, enabling the electrons to be easily injected to the conduction band of $\mathrm{AgBr}$. Simultaneously, the difference in work function between the bimetallic and $\mathrm{AgBr}$ formed a Schottky junction to facilitate the electron transfer until a Fermi equilibrium was achieved. The schematic of the mechanism of the bimetallic Au/AgBr-Ag heterostructure and the reactive oxygen species (ROS) formation reaction as reported by Purbia et al. is depicted in Figure 7 [103]. 
Another such similar finding was reported on the photoreduction of graphene oxide (GO) to graphene or reduced graphene oxide (rGO) by $\mathrm{Wu}$ et al. Their study revealed the photocatalytic Ag NP reduction at $\lambda>390 \mathrm{~nm}$ [95]. The schematic diagram representing the interaction of GO with $\mathrm{Ag}$ is shown in Figure 8. The LSPR effect on the Ag NPs generated a strong oscillating local electric field that enhanced the excitation of metallic charge carriers. The subsequently excited electrons were transferred to the conduction band of GO, yielding GO reduction and oxidation of Ag NPs [6].

Sun et al. described the role of Ag in the Ag@C composite. The composite displayed a broad LSPR absorption band at $\approx 630 \mathrm{~nm}$
[93]. The Ag@C nanocomposite exhibited excellent removal of aqueous rhodamine $\mathrm{B}$ and gaseous acetaldehyde $\left(\mathrm{CH}_{3} \mathrm{CHO}\right)$ under visible light irradiation. There have been some research reports on the combination of either $\mathrm{Pd}$ or $\mathrm{Pt}$ (considered to induce a reduced plasmonic effect) with $\mathrm{Au}$ or $\mathrm{Ag}$, (considered to induce an enhanced plasmonic effect) in which the former acts as an electron sinker for more efficient electron-hole pair separation [6]. For instance, Shuang et al. studied one such combination where they decorated $\mathrm{TiO}_{2}$ nanopillar arrays with both $\mathrm{Au}$ and Pt NPs and achieved a photocatalysis efficiency of 21 and 13 times higher than for pure $\mathrm{TiO}_{2}$. Their excellent results were attributed to the synergistic effect of Pt NPs which act as an electron trapper and the SPR of Au NPs [104].

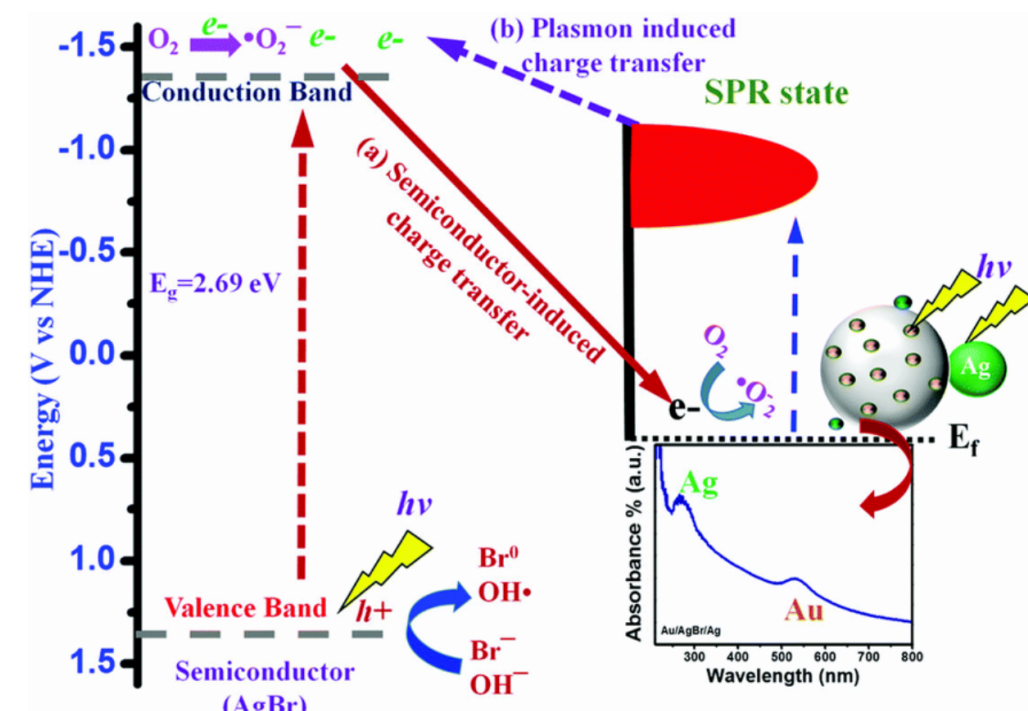

(AgBr) (a) Semiconductor-induced charge transfer

$\mathrm{AgBr}+h v \rightarrow \operatorname{AgBr}\left(\mathrm{h}^{+}\right)+\operatorname{AgBr}\left(\mathrm{e}^{-}\right)$

$\mathrm{M}+\operatorname{AgBr}\left(\mathrm{e}^{-}\right) \rightarrow \mathbf{M}\left(\mathrm{e}^{-}\right)$

$\mathrm{M}\left(\mathrm{e}^{-}\right)+\mathrm{O}_{2} \rightarrow \mathrm{M}+\cdot \mathrm{O}_{2}^{-}$

(b) Plasmon-induced charge transfer

$\mathrm{M}+\boldsymbol{h} v($ visible $) \rightarrow \mathbf{M}^{*}(\mathrm{M}=\mathrm{Au}, \mathrm{Ag})$

$\mathbf{M}^{*}+\operatorname{AgBr} \rightarrow \mathbf{M}+\operatorname{AgBr}\left(\mathrm{e}^{-}\right)$

$\operatorname{AgBr}\left(\mathrm{e}^{-}\right)+\mathrm{O}_{2} \rightarrow \mathrm{AgBr}+\cdot \mathrm{O}_{2}^{-}$

(c) General reactions

$\cdot \mathrm{O}_{2}{ }^{-}+\mathrm{H}^{+} \rightarrow \cdot \mathrm{HOO}$

$\mathrm{e}^{-}+\cdot \mathrm{HOO}+\mathrm{H}^{+} \rightarrow \mathrm{H}_{2} \mathrm{O}_{2}$

$\mathrm{H}_{2} \mathrm{O}_{2}+\mathrm{e}^{-} \rightarrow \cdot \mathrm{OH}+\mathrm{OH}^{-}$

Dye $+\cdot \mathrm{OH} \rightarrow \mathrm{CO}_{2}+\mathrm{H}_{2} \mathrm{O}$

Figure 7: Schematic of Au/AgBr-Ag heterostructure mechanism for improved photocatalytic performance. (a) Semiconductor-excited (AgBr) electron transfer to metal (Au or Ag) NPs. (b) Plasmon-excited electron (Au or Ag) transfer to semiconductor $(\mathrm{AgBr}) \mathrm{NPs}\left(\mathrm{e}^{-}=\mathrm{electron} \mathrm{h}^{+}=\mathrm{hole}, E_{\mathrm{f}}=\mathrm{Fermi}\right.$ energy, $\mathrm{M}=\mathrm{Au}$ or $\mathrm{Ag}$ ). (c) General reaction involved in mechanism of $\mathrm{Au} / \mathrm{AgBr}-\mathrm{Ag}$ heterostructure. Reprinted with permission from [103], copyright 2017 Royal Society of Chemistry.

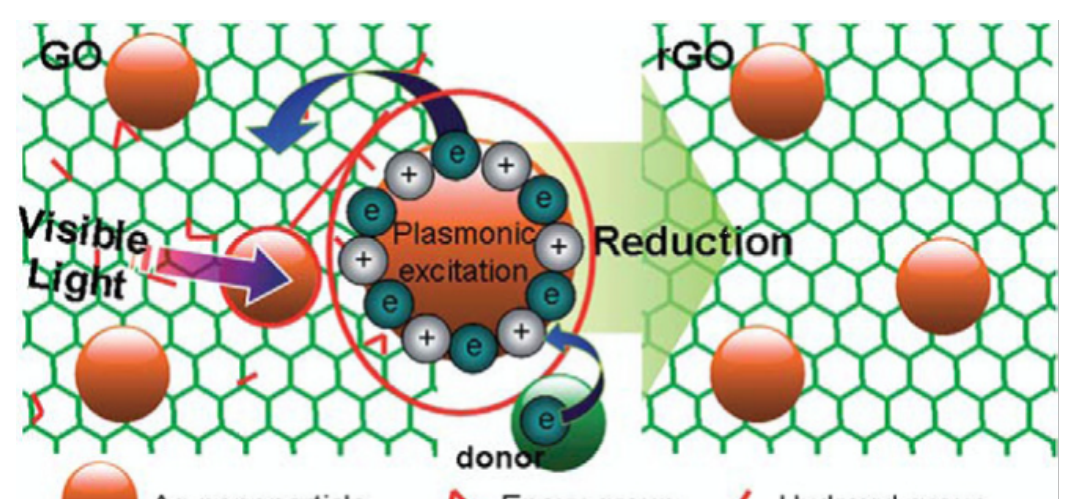

Ag nanoparticle $\wedge$ Epoxy group / Hydroxyl group

Figure 8: Photodegradation of GO in the presence of an electron donor (Ag NPs). Reprinted with permission from [95], copyright 2011 Royal Society of Chemistry. 


\section{Interactive plasmonic photocatalytic systems}

The various plasmonic photocatalytic systems differ with respect to the type of interaction between the noble metal and the semiconductor. The taxonomy of the plasmonic photocatalytic systems together with their interaction patterns are schematically explained in Figure 9 [6].

Figure $9 \mathrm{c}$ clearly shows the embedded form of the noble metal/ semiconductor system in which the metal is completely embedded into the semiconductor. This type of system benefits from the full advantages of Schottky junction formation with enhanced electron mobility as compared to partially embedded structures (Figure 9b). In addition, noble metal NPs that are embedded inside the semiconductor layer are less likely to dissolve, aggregate and detach. These advantages are helpful to increase the scattering of the NPs in the semiconductor and to confirm the stability of the photocatalysis reaction. However, noble metal NPs do not interact with the surrounding environment in this system (as do organic molecules in the solution) and thus lack the potential for redox reactions to occur. The generated charge carriers are trapped by the presence of noble metal. This leads to saturation when accumulating charge carrier reaches it limits. Thus, the gathered charges are finally trapped and allow a slow dispersion across the Schottky junction. However, in order to understand the mechanism of the LSPR effect, the Schottky junction, and the Fermi and mobilisation of electron/holes across the noble metal and semiconductor, either advanced characterisation tools or a theoretical simulation is necessary for detailed understanding of the circumstances.

\section{Advanced characterization and theoretical simulation}

The electron transfer mechanisms of plasmonic/semiconductor hybrid systems have been reported elsewhere. However, the principal mechanism that governs the plasmon excitation and electron injection into the semiconductor are still unclear. The verification that plasmon-excited electrons in Au NPs possess sufficient energy to overcome the Schottky junction to be injected into $\mathrm{TiO}_{2}$ was confirmed using high-resolution X-ray absorption spectroscopy (HR-XAS) [105]. The adopted experimental setup is depicted in Figure 10. The significant spectral variations observed by X-ray absorption spectroscopy (XAS) and resonant inelastic X-ray scattering (RIXS) suggest that electrons injected from Au NPs upon LSPR excitation could survive longer and become trapped at a Ti site near the surface of $\mathrm{TiO}_{2}$ [106]. More detailed work needs to be carried out to identify the individual contributions from different plasmonic effects such as hot-electron injection, generation of electromagnetic field and plasmon-induced heating [107]. The measurement of plasmonic photoelectrodes with polarized irradiation along various axes was combined with theoretical simulations based on the finite element method (FEM). In situ XAS was used to understand the electronic structural changes caused by the electromagnetic field upon the surface of plasmonic materials [108]. Designing the physical parameters of plasmonic metal nanostructures such as particle size, work function, surface facet and plasmonic band is a challenging task that demands numerical

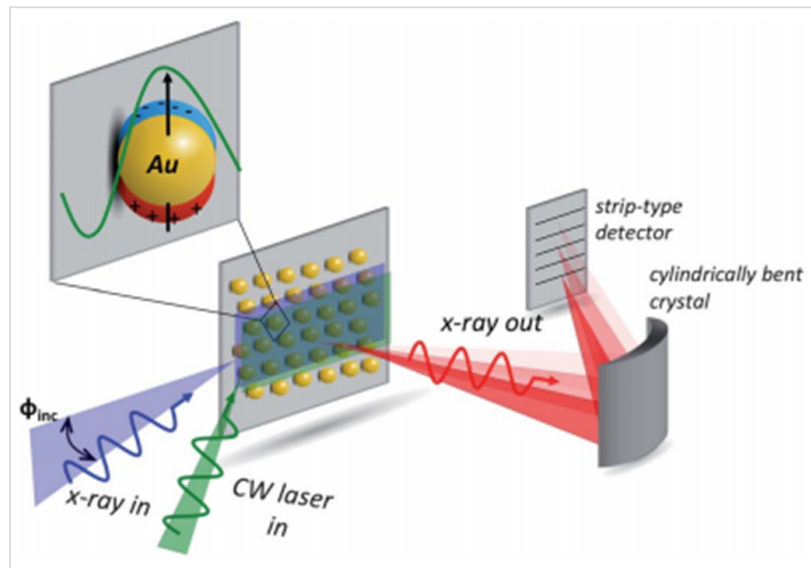

Figure 10: High-resolution X-ray absorption spectroscopy (HR-XAS) experiment used to determine the changes in the $A u L_{\text {III-edge induced }}$ by $100 \mathrm{~mW}$ continuous wave laser excitation of the localized surface plasmon at $532 \mathrm{~nm}$. Reprinted with permission from [105], copyright 2013 Royal Society of Chemistry.

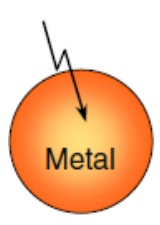

(a)

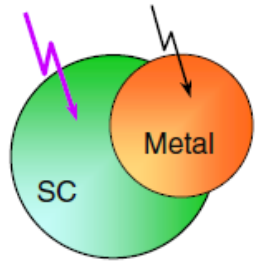

(b)

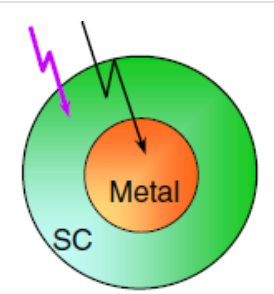

(c)

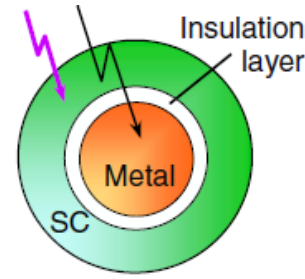

(d)

Figure 9: (a) Pure metal nanoparticles (NPs) without any semiconductor. (b) Metal NPs partially embedded into the semiconductor and partially exposed to the environment. (c) Metal NPs having a direct electrical contact by being fully embedded within the semiconductor without being exposed to the environment. (d) Metal NPs isolated from the semiconductor by a non-conducting layer to prevent direct electric contact. Reprinted with permission from [6], copyright 2013 IOP Publishing. 
simulation. It is known that the photocatalysis performance is affected by the noble metal particle size and thus finite difference time domain (FDTD) simulations were studied to reveal spectral and spatial features of the plasmonic field $[109,110]$. The FDTD simulations probe the effect of the particle size for optimizing the performance of catalytic systems. Some research groups have performed FDTD simulations to elucidate the contribution of the LSPR feature in the $\mathrm{Cu}_{7} \mathrm{~S}_{4} @ \mathrm{Pd}$ catalyst. They found that Pd NPs showed weak LSPR absorption at 808, 980 and $1500 \mathrm{~nm}$, while $\mathrm{Cu}_{7} \mathrm{~S}_{4}$ exhibited obvious electrical field enhancement at these wavelengths; thus $\mathrm{Cu}_{7} \mathrm{~S}_{4}$ was found to be the dominant contributor to the LSPR feature [111]. Using a similar simulation method, it was claimed that the enhanced photo-electrochemical water splitting performance of $\mathrm{Pd} @ \mathrm{BiVO}_{4}$ was attributed to the hot-electron injection from Pd NPs upon SPR excitation in the vis-NIR region [112].

\section{Identification of reactive radicals}

It is quite obvious that photocatalysis is supported by redox reactions caused by photo-induced formation of electrons $\left(\mathrm{e}^{-}\right)$ and holes $\left(\mathrm{h}^{+}\right)$. Several reactive species are produced on the heterogeneous solid surfaces of photocatalysts during the oxidative and reductive reactions in photocatalysis. Thus photocatalysis can be practically employed with water vapour under aerobic conditions, whereby photocatalysis involving oxygen $\left(\mathrm{O}_{2}\right)$ and water $\left(\mathrm{H}_{2} \mathrm{O}\right)$ as reaction species is vital. The species to which oxygen converts with high reactivity are generally called reactive oxygen species (ROSs) and four such major ROSs are recognized, namely hydroxyl radical $(\bullet \mathrm{OH})$, superoxide anion radical $\left(\cdot \mathrm{O}_{2}{ }^{-}\right)$, singlet oxygen $\left({ }^{1} \mathrm{O}_{2}\right)$ and hydrogen peroxide $\left(\mathrm{H}_{2} \mathrm{O}_{2}\right)$. Since the redox reaction takes place during the photocatalysis reaction, ROSs are produced sequentially both from $\mathrm{O}_{2}$ and $\mathrm{H}_{2} \mathrm{O}$ as illustrated in Figure 11 [113-115]. In general ROSs of $\bullet \mathrm{OH}, \mathrm{H}_{2} \mathrm{O}_{2}, \cdot \mathrm{O}^{2-}$ and ${ }^{1} \mathrm{O}^{2}$ would be generated in this order by the stepwise oxidation of $\mathrm{H}_{2} \mathrm{O}$. On the other hand, the stepwise reduction of $\mathrm{O}_{2}$ generates $\bullet \mathrm{O}^{2-}, \mathrm{H}_{2} \mathrm{O}_{2}$ and $\bullet \mathrm{OH}$.

The detection or quantification of these ROSs in the presence of a reactant pollutant is crucial for practical applications and such quantification can be correlated to the quantum efficiency (i.e., formation of ROSs for incident photon). Direct phosphorescence detection during the photocatalytic reaction would be beneficial for detection of ${ }^{1} \mathrm{O}_{2}$. For $\bullet \mathrm{OH}$, probing in solution could be observed from the surface reaction by perceiving the location of the probe molecules. In some cases the detection of - $\mathrm{O}_{2}{ }^{-}$and $\mathrm{H}_{2} \mathrm{O}_{2}$ after the photocatalytic reaction could be also possible. This review covers various studied detection methods used to identify the active radicals (quantum analysis) involved in the photocatalysis along with the uncertainties involved. Most of the reports of the present review concern ROSs in aqueous suspensions of photocatalyst powders. However, in

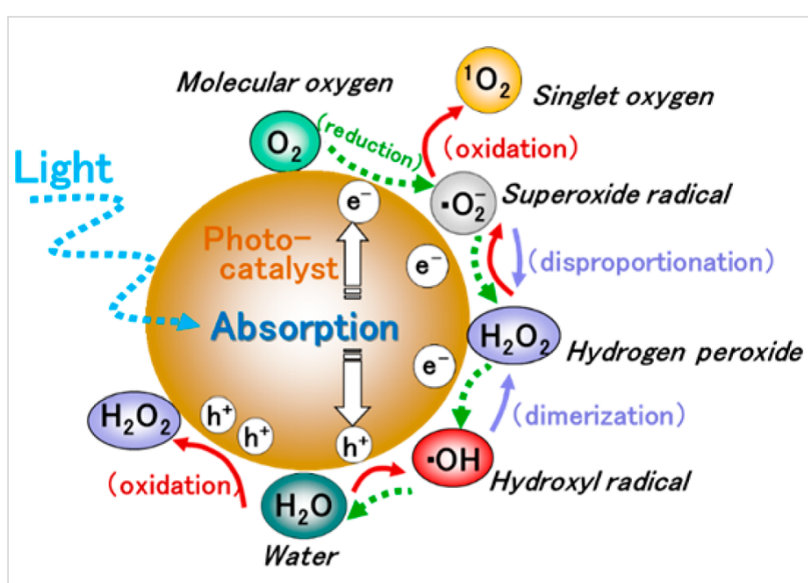

Figure 11: Generation of reactive oxygen species (ROSs) in the photocatalytic reduction and oxidation of $\mathrm{O}_{2}$ and $\mathrm{H}_{2} \mathrm{O}$. Reprinted with permission from [115], copyright 2017 American Chemical Society.

some cases, reactions under gaseous conditions, whose behaviour might be different from those in aqueous suspensions, were involved.

\section{Quantification methods for $\mathrm{H}_{2} \mathrm{O}_{2}$}

Although the generated ROSs subsequently decay, $\mathrm{H}_{2} \mathrm{O}_{2}$ is the most stable of the molecules and can be detected separately. As of now, various methods have been employed for its quantification in photocatalysis reactions and could be classified as (1) direct optical absorption in UV and IR regions, (2) coloration and (3) fluorescence probe.

\section{Direct optical absorption}

The direct detection of $\mathrm{H}_{2} \mathrm{O}_{2}$ in solution by measuring UV spectra is difficult due to the weak molar absorption coefficient of $\mathrm{H}_{2} \mathrm{O}_{2}\left(0.01 \mathrm{M}^{-1} \mathrm{~cm}^{-1}\right)$ at $360 \mathrm{~nm}$, which gradually increases up to $13 \mathrm{M}^{-1} \mathrm{~cm}^{-1}$ at the wavelength of $260 \mathrm{~nm}$ [115]. Meanwhile, the optical absorption in the IR region can be detected by observing the peak of $\mathrm{O}-\mathrm{O}$ stretching of $\mathrm{H}_{2} \mathrm{O}_{2}$. Figure 12 shows three plausible types of structural formation of adsorbed $\mathrm{H}_{2} \mathrm{O}_{2}$ on to the surface of $\mathrm{TiO}_{2}$. A side-on peroxide structure (Figure 12c) appeared for the absorption band on rutile at
A

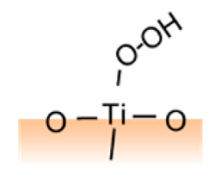

end-on

(on-top)
B

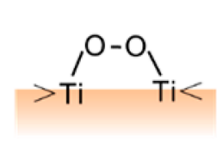

bridged

( $\mu$-peroxide)
C

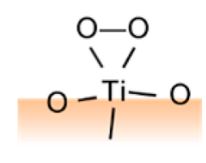

side-on ( $\eta^{2}$-peroxide)
Figure 12: Plausible structural formation of adsorbed $\mathrm{H}_{2} \mathrm{O}_{2}$ on $\mathrm{TiO}_{2}$ surface (a) end-on (b) bridged and (c) side-on. Reprinted with permission from [115], copyright 2017 American Chemical Society. 
$820-940 \mathrm{~cm}^{-1}$ [113]. The peaks at 838 and $877 \mathrm{~cm}^{-1}$ were assigned to the end-on peroxide (see Figure 12a), and that at $812 \mathrm{~cm}^{-1}$ was assigned to the bridged peroxide (see Figure 12b) [115]. The signal observed at $928 \mathrm{~cm}^{-1}$ was tentatively assigned to the triangle peroxide (see Figure 12c) [115].

\section{Coloration methods}

Coloration is another common method adopted for the quantification of $\mathrm{H}_{2} \mathrm{O}_{2}$. In this method, iodide [116,117], $\mathrm{Ti}^{4+}$ ions [118] and $N, N$-dimethyl-p-phenylenediamine (DPD) $[119,120]$ were used to detect $\mathrm{H}_{2} \mathrm{O}_{2}$ during photocatalysis. For the iodide method, the solution was mixed with KI and sodium acetate buffer containing a few drops of catalyst (ammonium dimolybdate) for the oxidation of $\mathrm{I}^{-}$by $\mathrm{H}_{2} \mathrm{O}_{2}$. Thus, $\mathrm{I}^{3-}$ was obtained in the solution and was measured at $360 \mathrm{~nm}$. Alternatively, when $\mathrm{Ti}^{4+}$ ions were used as indicators, yellow-coloured metal complexes with $\mathrm{H}_{2} \mathrm{O}_{2}$ were formed and examined at $410 \mathrm{~nm}$. [118]. The DPD method is based on the oxidation of DPD by $\mathrm{H}_{2} \mathrm{O}_{2}$ catalysed with horseradish peroxidase. The radical cation $\mathrm{DPD}^{+}$ exhibits a fairly stable colour with an absorption peak at $551 \mathrm{~nm}$ $[119,120]$.

\section{Fluorescent probe}

In this method a fluorescent dimer is created by reacting determining species $\left(\mathrm{H}_{2} \mathrm{O}_{2}\right)$ with p-hydroxyphenyl- acetic acid mediated with horseradish peroxidase as a catalyst. The complete reaction scheme is explained in Figure 13a [115]. The intensity of the generated fluorescence is analysed using a fluorescence spectrophotometer with an emission wavelength of $408.5 \mathrm{~nm}$ excited at $316.5 \mathrm{~nm}$. The concentration of the peroxide is directly proportional to the intensity of the created fluorescence as explained by the Beer-Lambert law [121-123]. Alternatively, a fluorescence probe reagent, dihydrorhodamine 123 was also reported to detect $\mathrm{H}_{2} \mathrm{O}_{2}$ in photocatalytic systems where dihydrorhodamine 123 is oxidized to a fluorescent molecule, rhodamine 123 , by the reaction with $\mathrm{H}_{2} \mathrm{O}_{2}$ and peroxidase as shown in Figure 13b [115].

\section{Detection methods for ${ }^{1} \mathrm{O}_{2}$}

${ }^{1} \mathrm{O}_{2}$ is singlet oxygen, which is an excited state of $\mathrm{O}_{2}$. It can be deactivated to the original stable $\mathrm{O}_{2}$ without being involved in chemical reactions or electron transfer. The detection methods of ${ }^{1} \mathrm{O}_{2}$ are focussed on (1) electron magnetic resonance and (2) fluorescence probe methods.

\section{Electron spin resonance detection with probe reagents}

For the detection of singlet oxygen in photocatalysis, 4-hydroxy-2,2,6,6-tetramethylpiperidine (HTMP), a wellknown stable nitroxide radical (4-hydroxy-2,2,6,6-tetramethylpiperidine 1-oxyl, TEMPOL) is used to generate the corresponding 1-oxyl radical by the reaction with ${ }^{1} \mathrm{O}_{2}$ [124]. The final product is subjected to electron spin resonance (ESR) for the quantification of ${ }^{1} \mathrm{O}_{2}$ as shown in Figure 14a.<smiles>O=C(O)Cc1ccc(O)cc1</smiles>

p-Hydroxyphenylacetic acid

B<smiles>COC(=O)c1ccccc1C1c2ccc(N)cc2Oc2cc(N)ccc21</smiles>

\section{peroxidase}

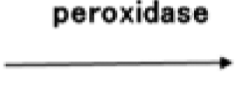<smiles>O=C(O)Cc1ccc(O)c(-c2cc(CC(=O)O)ccc2O)c1</smiles>

\section{p-Hydroxyphenylacetic acid dimer}

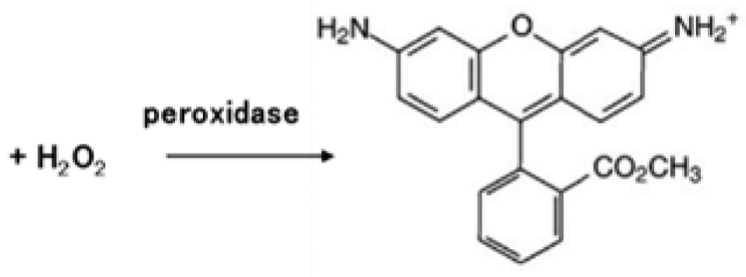


A<smiles>CC1(C)CC(O)CC(C)(C)N1</smiles><smiles>CC1(C)CC(O)CC(C)(C)N1O</smiles>

HTMP

B

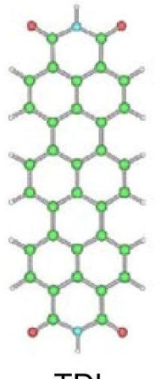

TDI

weak fluorescence

\section{$\underset{\text { cycloaddition }}{\stackrel{{ }^{1} \mathrm{O}_{2}\left(\mathrm{a}^{1} \Delta_{\mathrm{g}}\right)}{\longrightarrow}}$}

TDI endoperoxide less fluorescence

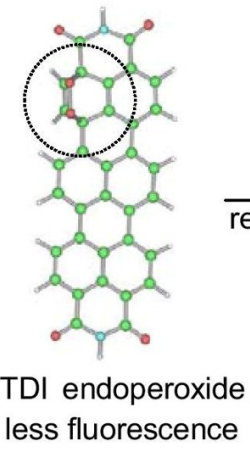

TEMPOL

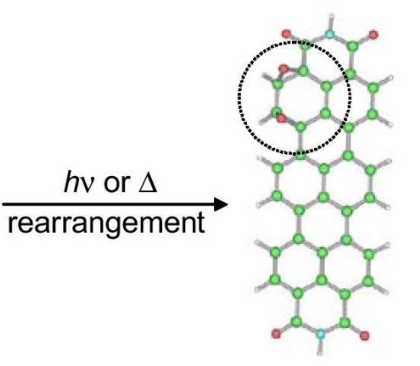

TDI diepoxide strong fluorescence blue shift (ca. $70 \mathrm{~nm}$ )

Figure 14: (a) Reaction of HTMP to TEMPOL. Reprinted with permission from [115], copyright 2017 American Chemical Society. (b) Fluorescence detection of ${ }^{1} \mathrm{O}_{2}$ with TDI. Reprinted with permission from [125], copyright 2007 Springer Science + Business Media.

A terrylene diimide (TDI) derivative that can produce fluorescent diepoxide through cycloaddition (Figure 14b) was adopted to detect ${ }^{1} \mathrm{O}_{2}$ generated in air. This TDI derivative is usually coated on a glass plate and faced the photocatalyst with an air gap through which ${ }^{1} \mathrm{O}_{2}$ diffuses. The detection of single-molecule fluorescence can be observed using a light microscope $[125,126]$.

Finally, since the ${ }^{1} \mathrm{O}_{2}$ species possess paramagnetic properties caused by the orbital angular momentum, they can be quantified by direct ESR detection [127]. Therefore, an ESR spectrometer with a microwave frequency of about $9 \mathrm{GHz}$ (X-band) could be used to observe the quartet signal of ${ }^{1} \mathrm{O}_{2}$ in the gas phase at $950 \mathrm{mT}$. Nevertheless, this detection method has not yet been applied to detect ${ }^{1} \mathrm{O}_{2}$ produced during photocatalysis.

\section{Detection methods of $\cdot \mathrm{OH}$}

The $\bullet \mathrm{OH}$ radical is often regarded as the most effective reactant for photocatalytic decomposition. Among the various ROSs, the rate constant of $\bullet \mathrm{OH}$ is almost at the diffusion limit and hence the reactivity of $\cdot \mathrm{OH}$ is considerably high. The detection methods utilized for $\bullet \mathrm{OH}$ in photocatalysis are focussed on (1) laser-induced fluorescence (LIF), (2) spin-trapping ESR and (3) fluorescent probe methods.

\section{Laser-induced fluorescence methods}

This highly sensitive method is employed to detect an low concentration of $\bullet \mathrm{OH}$ radicals in the atmosphere. Figure $15 \mathrm{a}$ shows the experimental framework to measure the $\cdot \mathrm{OH}$ radicals generated from irradiated $\mathrm{TiO}_{2}$ [128]. A dye laser, which acts as a source of the emission wavelength at $310 \mathrm{~nm}$, was used to calculate the intensity of the fluorescence emitted from $\bullet \mathrm{OH}$ radicals. The $\cdot \mathrm{OH}$ radicals emitted from the photoexcited $\mathrm{TiO}_{2}$ surface to the gas phase were confirmed by the LIF spectrum (see Figure 15b) with the characteristic rotational structure of the transition energies [115].

\section{Spin-trapping electron spin resonance}

Spin-trapping ESR is a conventional method and most often utilized to detect the $\cdot \mathrm{OH}$ generated in biological systems with the support of a spin-trapping reagent, namely 5,5-dimethyl-1pyrroline $N$-oxide (DMPO) $[129,130]$. The unstable $\cdot O H$ radicals released during the photocatalysis react with DMPO to convert stable DMPO-OH radicals and are detected by ESR spectroscopy. There is a high probability that the valenceband holes might alternatively oxidize the spin-trapping reagents before the formation of $\bullet \mathrm{OH}$ radicals. Figure 16 shows a three-step process for DMPO-OH radical formation in photocatalysis. 


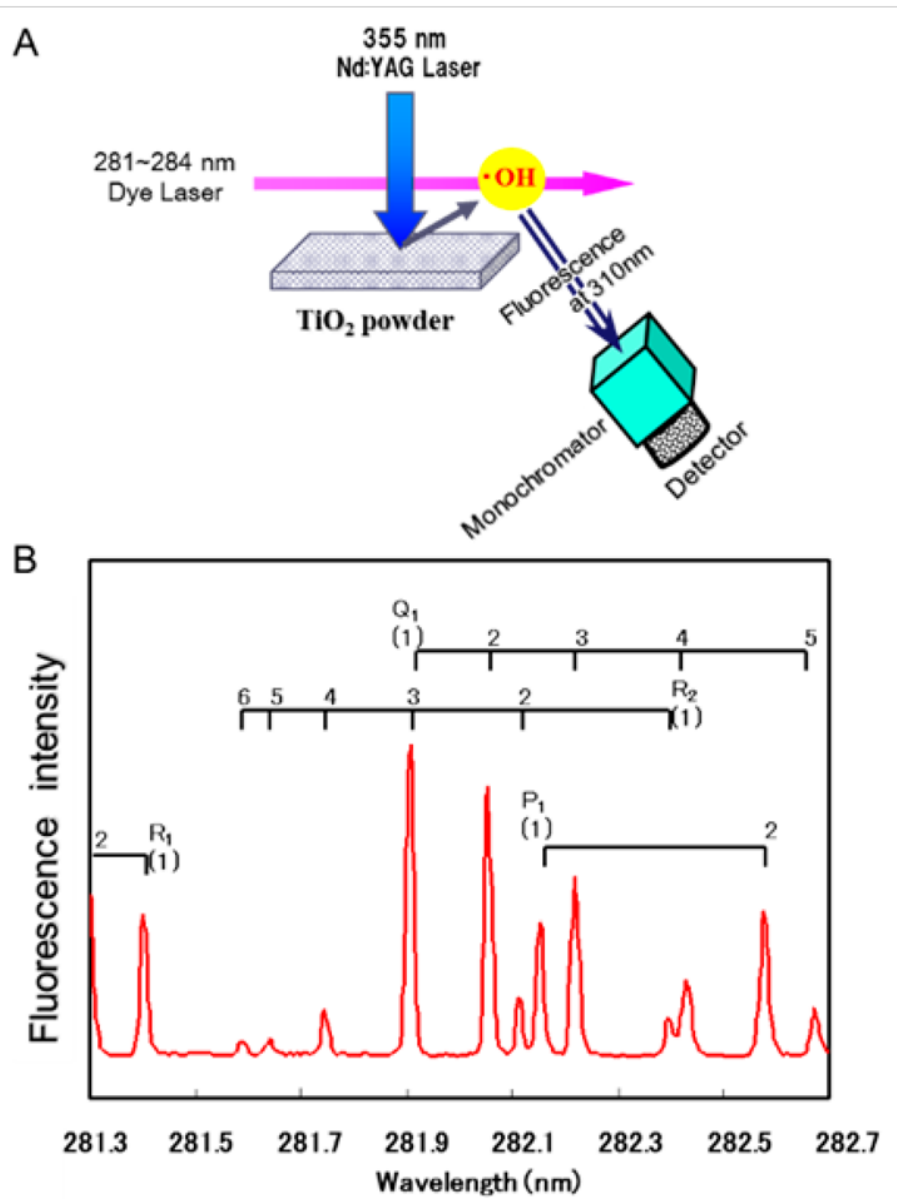

Figure 15: (a) Laser-induced fluorescence detection of $\bullet \mathrm{OH}$ released from an irradiated $\mathrm{TiO}_{2}$ surface. Reprinted with permission from [128], copyright 2007 American Chemical Society. (b) Obtained excitation spectrum of $\bullet \mathrm{OH}$ radicals. Reprinted with permission from [115], copyright 2017 American Chemical Society.

A

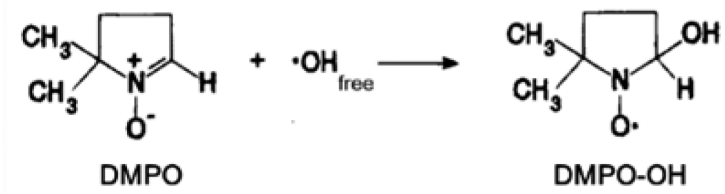

B

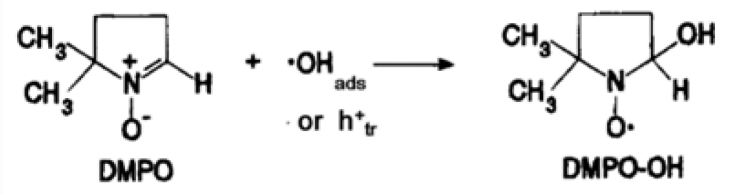

C

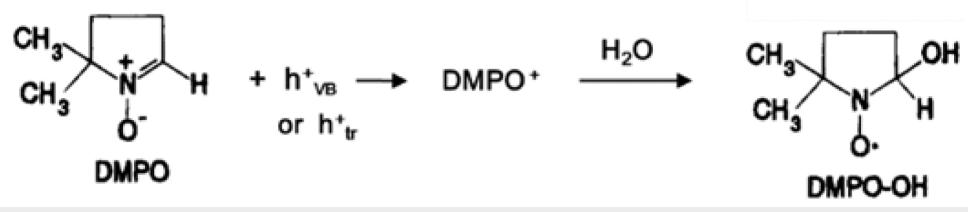

Figure 16: Reaction routes for detection of $\cdot \mathrm{OH}$ radicals with a DMPO spin-trapping reagent. Reactions with $\cdot \mathrm{OH}$ radicals (a) in solution, (b) at the surface, and (c) indirect reaction via oxidation of DMPO. Reprinted with permission from [115], copyright 2017 American Chemical Society. 


\section{Fluorescent probe}

The fluorescein, 3-( $p$-hydroxyphenyl)fluorescein (HPF) and 3-( $p$-aminophenyl)fluorescein (APF) dyes have been used as reagents in photocatalytic reactions [131]. A strongly emissive fluorescein molecule, as shown in Figure 17a, was formed when HPF selectively reacts with $\bullet \mathrm{OH}$ radicals. However, it does not react with the other ROSs, such as $\bullet \mathrm{O}_{2}^{-},{ }^{1} \mathrm{O}_{2}$, and $\mathrm{H}_{2} \mathrm{O}_{2}$. A fluorescein-coated glass plate supported with HPF molecules is employed and a silanol group separates the $\mathrm{TiO}_{2}$ coating glass plate with a spacer, as shown in Figure 17b. Polyimide films were used to control the distance between the two glass plates, and the space was filled with air-saturated water. In this way, it was confirmed that the $\bullet \mathrm{OH}$ generated on the photocatalysts could diffuse to the HPF-coated glass.

\section{Detection methods of $\cdot \mathrm{O}_{2}^{-}$}

\section{Spin-trapping electron paramagnetic resonance}

The detection the $\cdot \mathrm{O}_{2}{ }^{-}$in aqueous solution by EPR can be performed with the presence of DMPO as the trapping agent
(Figure 18a). Unfortunately the reaction rates of DMPO with $\cdot \mathrm{O}_{2}{ }^{-}$and $\cdot \mathrm{O}_{2} \mathrm{H}$ are extremely small as compared with the $\cdot \mathrm{OH}$ radical. In addition, the $\cdot \mathrm{O}_{2}{ }^{-}$, which is drawn to DMPO, is unstable and it converts to $\cdot \mathrm{OH}$ adducts (Figure 18a).Thus, the detection of $\bullet \mathrm{O}_{2}{ }^{-}$with DMPO is not facile [115].

Spin-trapping reagents such as 5-diethoxyphosphoryl-5-methyl1-pyrroline $N$-oxide (DEPMPO) [132] and 5-tert-butoxycarbonyl-5-methyl-1-pyrroline $N$-oxide (BMPO) [133] and 5-(2,2dimethyl-1,3-propoxycyclophosphoryl)-5-methyl-1-pyrroline $\mathrm{N}$-oxide (CYPMPO) [134] have been reported. The chemical structures of these reagents are explained in Figure $18 \mathrm{~b}$.

\section{Future perspective}

Even though remarkable progress has been achieved in this area of research, some challenges are still to be met. The future perspective on the realistic application of plasmonic photocatalysts will focus on the scalability, cost and sustainability from the perspective of synthesis route to application. In addition, the

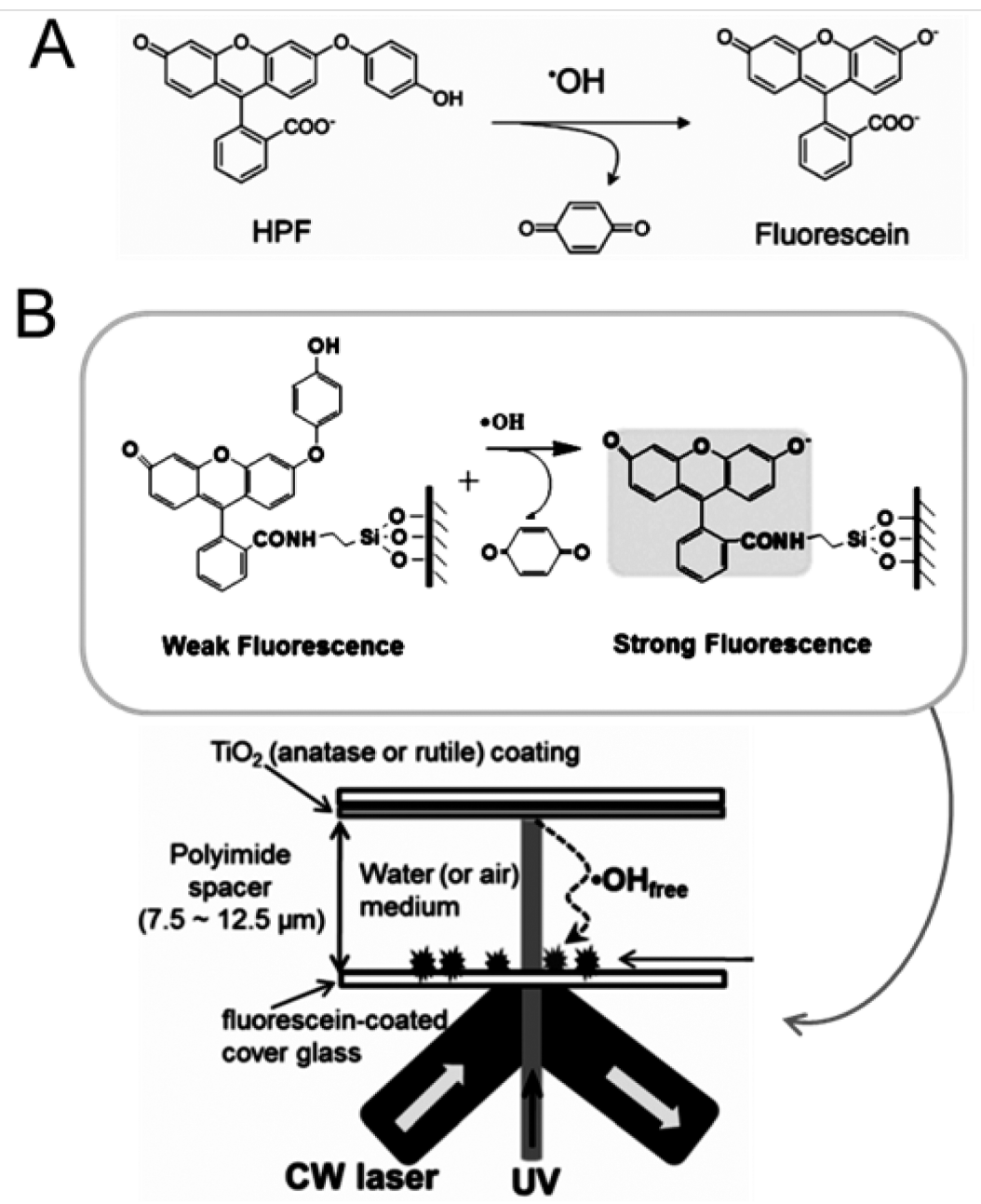

Figure 17: (a) Usage of fluorescence probe HPF to detect $\cdot \mathrm{OH}$ radicals. (b) Experimental setup for the single-molecule detection of photogenerated $\cdot \mathrm{OH}$ in $\mathrm{H}_{2} \mathrm{O}$. Reprinted with permission from [131], copyright 2014 Wiley-VCH Verlag GmbH \& Co. 
A

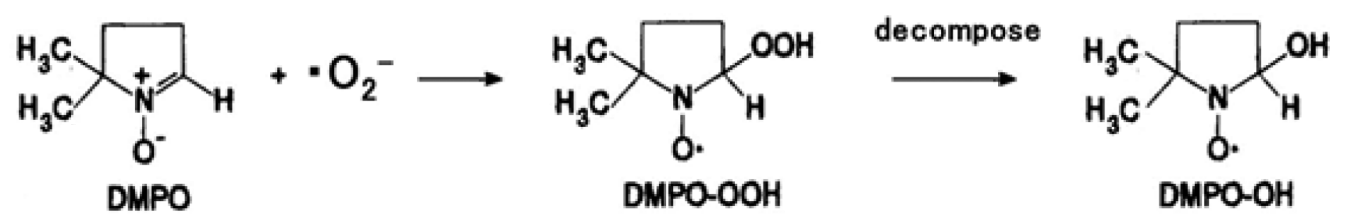

B<smiles>CC(C)(C)OC(=O)C1(C)CCCN1[O-]</smiles>

BMPO<smiles>CCOP(=O)(OCC)C1(C)CCCN1O</smiles>

DEPMPO<smiles>CC1(C)COP(=O)(C2(C)CCC=N2)C(=O)O1</smiles>

CYPMPO

Figure 18: (a) Reactions involved in the detection of $\cdot \mathrm{O}_{2}{ }^{-}$with DMPO. (b) Chemical structures of the spin-trapping reagents for $\cdot \mathrm{O}_{2}{ }^{-}, \mathrm{BMPO}$, DEPMPO and CYPMPO. Reprinted with permission from [115], copyright 2017 American Chemical Society.

theory behind the plasmonic-induced electron transfer mechanism still remains questionable and thus necessitates the advanced characterization and theoretical simulation at the electronic level.

\section{Near-infrared plasmonic materials for optimized solar absorption}

In the preceding decades, much research was focused on the application of $\mathrm{Au}$ and $\mathrm{Ag}$ as plasmonic metals for utilising the visible region that consists of $\approx 43 \%$ of the solar spectrum against NIR [135]. The high carrier concentration $\left(\approx 5.9 \times 10^{22} \mathrm{~cm}^{-3}\right)$ of Au and Ag enables their intense LSPR excitations in the visible region [136]. The resonance in both $\mathrm{Au}$ and $\mathrm{Ag}$ can be controlled, but their high resistive loss, earth rarity and high cost are all disadvantages which limit them from being produced in large scale for real-world applications [21]. It is well-known that NIR wavelengths $(760-3000 \mathrm{~nm})$ account for $\approx 54 \%$ of the solar spectrum compared to the visible, which necessitates the search for plasmonic materials capable of utilising photons across the NIR region [137]. Compared to Au and $\mathrm{Ag}$, conducting oxides and semiconductor nanomaterials possess lower carrier concentrations that are useful for their resonance in the NIR range [16]. For example, when coupled with $\mathrm{Pd}$, copper chalcogenide $\left(\mathrm{Cu}_{7} \mathrm{~S}_{4}\right)$ utilizes NIR range photons through LSPR, and Pd traps the hot-holes for photocatalysis reactions, including oxidation of benzyl alcohol, hydrogenation of nitrobenzene and the Suzuki coupling reaction. The strong electrical field intensity at $1500 \mathrm{~nm}$ (Figure 19) reveals that the LSPR is more significant when the irradiation wavelength is near to the $\mathrm{Cu}_{7} \mathrm{~S}_{4}$ LSPR peak [111]. Likewise, tungsten oxide
$\left(\mathrm{WO}_{3-\delta}\right)$ nanocrystals showed intense NIR absorption with an LSPR peak at $\approx 900 \mathrm{~nm}$ [138]. The plasmonic resonance of semiconductors could be manipulated by tuning the stoichiometric composition, dopant concentration, or phase transitions $[139,140]$. The manipulation of the stoichiometric ratio of semiconductors could increase the free-charge density and promote the LSPR arising from collective oscillations of excess free charges on semiconductor surface, thus enhancing the NIR absorption abilities [141,142]. Interestingly, $\mathrm{Cu}_{2-x} \mathrm{Se}$ nanocrystals (NCs) showed distinct NIR plasmon band due to the formation of copper vacancies in the material through exposure to oxygen or to a Ce(IV) complex [143]. Similarly, the LSPR band in stoichiometric $\mathrm{Cu}_{2-x} \mathrm{~S}, \mathrm{Cu}_{2-x} \mathrm{Se}$ and $\mathrm{Cu}_{2-x} \mathrm{Te}$ was improved by converting them into their nonstoichiometric counterparts via oxidation/reductive reactions [142]. Besides, the carrier concentration of aluminium-doped zinc oxide (AZO) can be shifted from 0.5 to $10 \times 10^{20} \mathrm{~cm}^{-3}$ by varying the concentration of $\mathrm{Al}$, thus contributing to the wide-range SPR $(2200-880 \mathrm{~nm})$ [144]. Despite the tunable plasmonic features of semiconductors, some plasmonic semiconductors are photocatalytically inert due to their unfavourable band edge position compared to the redox potential of targeted species. An effective approach to overcome this restriction was to integrate the nonstoichiometric materials (tungsten oxide $\left.\left(\mathrm{W}_{18} \mathrm{O}_{49}\right)\right)$ with graphitic carbon nitride $\left(\mathrm{g}-\mathrm{C}_{3} \mathrm{~N}_{4}\right)$. The $\mathrm{g}-\mathrm{C}_{3} \mathrm{~N}_{4}$ was used to effectively capture the LSPR-excited hot electrons from $\mathrm{W}_{18} \mathrm{O}_{49}$, enabling an efficient photocatalytic reaction [145]. Similarly, $\mathrm{TiO}_{2}$ was coupled with $\mathrm{W}_{18} \mathrm{O}_{49}$ for effective photocatalysis under full solar spectrum conditions. Another advantage of such hybrid nanostructures is their ability to facilitate the spatial charge separation of photoin- 


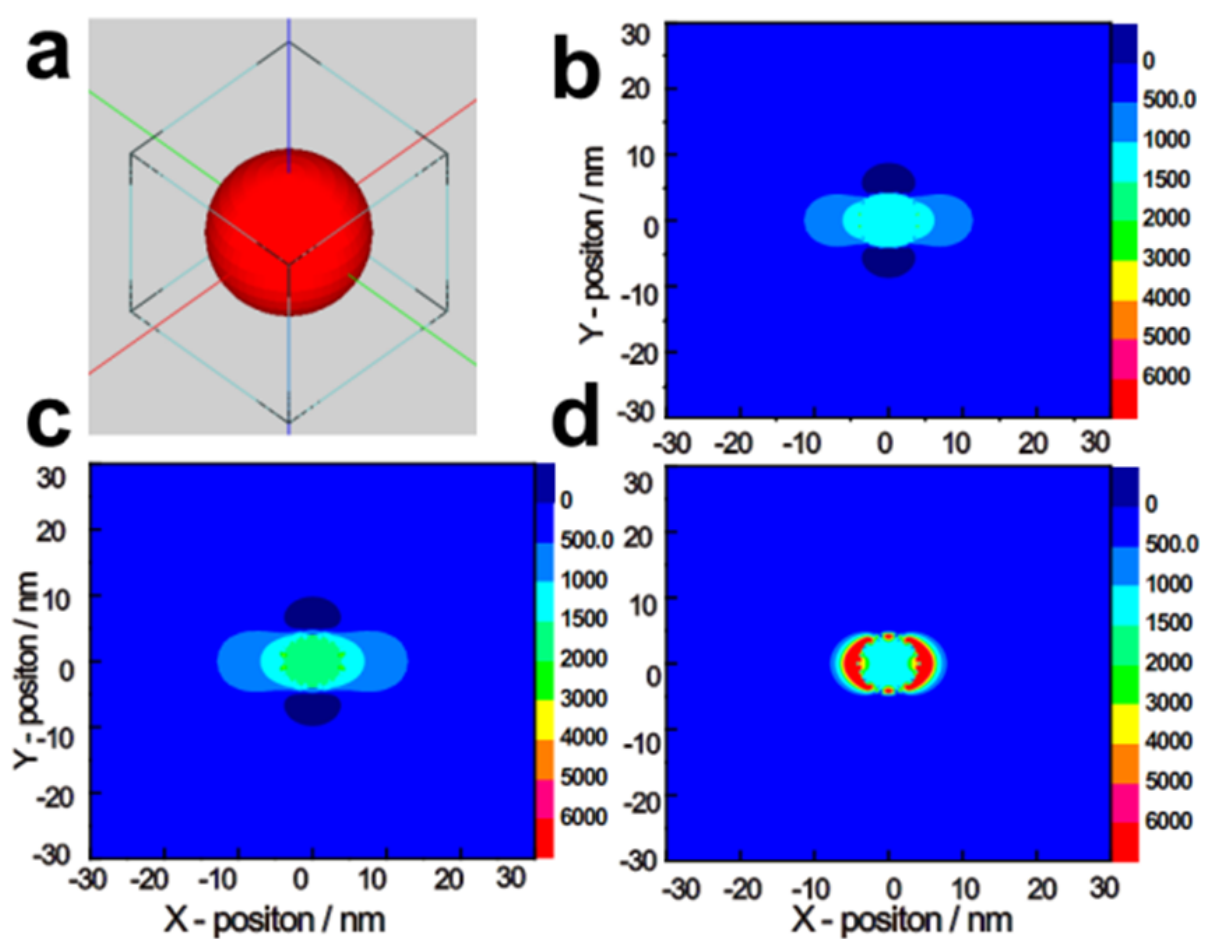

Figure 19: (a) FDTD simulation set up for $\mathrm{Cu}_{7} \mathrm{~S}_{4}$. (b-d) $2 \mathrm{D}$ contour map of the electric field intensities around the $\mathrm{Cu}_{7} \mathrm{~S}_{4}$ nanocrystal under illumination at $808 \mathrm{~nm}$ (b), $980 \mathrm{~nm}$ (c) and $1500 \mathrm{~nm}$ (d), respectively. Reprinted with permission from [111], copyright 2015 American Chemical Society.

duced carriers by creating an alternate permutation of band edges at the interface [146]. Some researchers found that both titanium nitride ( $\mathrm{TiN})$ and zirconium nitride $(\mathrm{ZrN})$ displayed similar optical properties as $\mathrm{Au}$ and can replace Au NPs for vis-NIR light absorption [147,148].

\section{Bio-inspired plasmonic nanostructures/architectures} The pioneering works of several research groups have revealed that by mimicing biological systems, such as butterfly wings [149] and snake skin [150], systems can be designed that are cable of absorbing NIR light due to their distinctive nanoarchitectures with underlying mechanisms. For example, the velvet black scales on snake skins have been shown to demonstrate four times better absorbance than other scales in the UV-NIR spectrum range due to their hierarchical pattern of leaf-like microstructures with nanoridges [150]. In other case, the geometry of the scales of a butterfly promote a light trapping effect from the UV to NIR range, which significantly increases the light absorption compared to a non-patterned system [149] These works inspired the combination of bismuth vanadate $\left(\mathrm{BiVO}_{4}\right)$ with the 3D architecture design of a butterfly wing, in addition to gold nanorods (NRs) as plasmonic nanoantennas for an effective far red-to-NIR photocatalytic conversion. The electron-hole pairs were formed in some parts of BVO when $\mathrm{BiVO}_{4}$ encountered intense SPR-induced electric fields localized at Au NRs, and hence the entire photocatalytic system could function under red-to-NIR irradiation [151]. All these studies provide new insight into using plasmonic nanoarchitectures for photocatalysis applications in the future. Similarly, biomimetic assembly methods can also be used to arrange plasmonic metals ( $\mathrm{Au}$ and $\mathrm{Ag}$ ) with molecular-level precision to achieve tunable light absorption and emission. Prior works reported the use of DNA oligonucleotides [152,153] and virus capsids [154] as tunable spacers to control the distance between $\mathrm{Au}$ NPs and fluorophores. The assembly hierarchy of the plasmonic photocatalysts were carried out using both MS2 virus capsids and DNA origami as biological scaffolds to increase fluorescence intensity by tuning the distance between capsid and $\mathrm{Au}$ NPs [155]. In recent years, the phytochemicals present in plant-based and waste materials have been used as reducing and stabilizing agents to prepare plasmonic metals (Au and Ag). The so called green synthesis of Au and Ag are suitably used in clinical and biomedical fields because it is free of toxic chemicals and non-polar solvents. Numerous researches have proved that $\mathrm{Au}$ and Ag NPs can be synthesized from the chemicals extracted from plants and microorganisms such as fungi, algae, bacteria and yeasts [156-161]. Different types of biomolecules available in plants, for example, polysaccharides, phenolics, or flavonoids are capable of producing metal nanoparticles of different sizes and shapes [162]. This phytosynthesis is more favourable than that which occurs in microorganisms because it is fast and cost effective and can be readily scaled for realistic 
applications [163]. A very recent study demonstrated that $\mathrm{Ag} / \mathrm{AgCl}$ can be synthesized using ash gourd peel extract without using organic toxic solvents [157]. Bovine serum albumin (BSA) and Neem extract were used to prepare Ag-ZnO nanostructures, in which both green extracts acted as a shape controllers and reducing agents of $\mathrm{Ag}^{+}$to overcome the self-nucleation problem of Ag NPs [164,165].

\section{Direct photocatalysis by plasmonic metals}

Plasmonic catalyst systems have almost exclusively focused on the coupling of plasmonic metals ( $\mathrm{Au}$ and $\mathrm{Ag}$ ) with semiconductors. Recent reports found that plasmonic metals can be utilised to motivate direct photocatalysis where both light harvesting and activation of reactants take place on the plasmonic metals. It is observed that, unlike semiconductors, the photocatalytic quantum efficiency on plasmonic metal enhances the light intensity and thermal energy absorption. This result shows that plasmonic metals are effective at coupling thermal and photonic stimuli for driving chemical transformations [166]. The rapid recombination of plasmon charge carriers restricted the direct photocatalysis reaction on metal surfaces; however, the energy obtained as a result of recombination facilitated thermal reaction and resolved this drawback [167]. Since the foremost discovery of primary photocatalysis by Au NPs through LSPR [168], numerous reactions have been performed on $\mathrm{Ag}, \mathrm{Au}$, and $\mathrm{Cu}$ surfaces, showing that low intensity visible photon irradiation significantly enhances the rate of chemical reactions. A pioneering work showed that Au NPs have potential in degrading volatile organic compounds, $\mathrm{HCHO}$ to $\mathrm{CO}_{2}$, under 600-700 nm red light irradiation [168]. The same group also reported the use of Ag NPs to remove phenol and drive oxidation of benzyl alcohol to benzaldehyde under UV light. This verifies the role of the LSPR effect and interband transition of Ag NPs in activating organic molecules for oxidation under UV-vis irradiation [169]. Au NPs are more suitable for immediate plasmonic photocatalysis compared to other plasmonic metals because they are more chemically resistant and stable to standard atmosphere [170]. Under LED excitation at $530 \mathrm{~nm}$ in the presence of air or oxygen, Au NPs could promote the oxidation reaction of 9- anthraldehyde to form anthraquinone as the dominant product [171]. As compared to semiconductors like $\mathrm{TiO}_{2}$, the ability of Au NPs to conduct plasmonic-induced reductions at lower temperature and pressure enable the selection of unstable intermediates of a thermal reaction as the product (e.g., aromatic azo compounds). These findings show the potential of Au NPs in utilizing the solar spectrum, also in temperature-sensitive synthesis [172]. Most reported works on direct photocatalysis are limited only to plasmon-induced chemical transformations. Very few have moved away from this traditional route to demonstrate the feasibility of electrocatalytic oxidation adopting glucose accelerated by Au NPs upon
LSPR excitation under a suitable voltage bias. The hot electrons injected from Au NPs can be driven into the external circuit to deliver appreciable current, while the holes facilitate the electrocatalytic oxidation of glucose owing to their equal energy levels. This constructive finding propelled the potential applications of electrochemical energy conversion, electroanalysis and electrochemical devices [173]. Overall, it is clear that the plasmonic metals are able to concentrate and channel the energy of low intensity visible light into adsorbed molecules to promote significant enhancement in the rate of chemical transformation. Furthermore, there are certain cases that have showed primary evidence for direct plasmon-driven photocatalysis capable of controlling catalytic selectivity through different reaction mechanisms. Gold NPs on $\mathrm{CeO}_{2}$ were found to be efficient at reducing a wide range of epoxides, azo compounds, and ketones at ambient temperature under visible light. Their reduction potential highly depends on the incident wavelength [174]. The team revealed the selectivity tuning by plasmon-mediated photo-switching and demonstrated the same for propylene epoxidation on $\mathrm{Cu}$ NPs in which the reduction of the $\mathrm{Cu}_{2} \mathrm{O}$ shell was brought on by the plasmon-excited $\mathrm{Cu}$ [175].

\section{Conclusion}

This review explicitly detailed insight into plasmonic photocatalysts as a potential candidate for enhanced utilisation of the solar spectrum. The topic of the review was detailed through fundamental explanations together with the various synthesis routes. The review also clarified the mechanism of LSPR for the various noble metal nanoparticles in addition to the Schottky phenomenon on the studied metal oxide photocatalysts. An in-depth analysis on the formation and identification of ROSs and their interaction with pollutants was clearly presented. The future prospects of these sustainable photocatalysts with real-time applications for energy storage and environmental remediation were thoroughly reviewed. The present review also revealed the potential of plasmonic photocatalysts as an alternative sustainable approach and new direction for effectively harnessing sunlight to fulfil global environmental issues and aid to the energy crisis.

\section{Acknowledgements}

The corresponding author is grateful to Science and Engineering Research Board [SERB], Department of Science and Technology for the financial support received under the Early Career Research Award with grant code ECR/2016/001400. This work was also supported by Universiti Tunku Abdul Rahman Research Fund, UTARRF (IPSR/RMC/UTARRF/ 2016-C2-L05), (IPSR/RMC/UTARRF/2017-C1/S04) and Universiti Malaysia Pahang Internal Grant, RDU 160317 and RDU 1603137. 


\section{$\mathrm{ORCID}^{\circledR}$ iDs}

Pichiah Saravanan - https://orcid.org/0000-0001-8302-9586

\section{References}

1. Zhou, X.; Liu, G.; Yu, J.; Fan, W. J. Mater. Chem. 2012, 22, 21337-21354. doi:10.1039/C2JM31902K

2. Ong, W.-J.; Tan, L.-L.; Chai, S.-P.; Yong, S.-T.; Mohamed, A.-R ChemSusChem 2014, 7, 690-719. doi:10.1002/cssc.201300924

3. Kochuveedu, S. T.; Jang, Y. H.; Kim, D. H. Chem. Soc. Rev. 2013, 42, 8467-8493. doi:10.1039/C3CS60043B

4. Chen, H.; Sun, Z.; Ni, W.; Woo, K. C.; Lin, H.-Q.; Sun, L.; Yan, C.; Wang, J. Small 2009, 5, 2111-2119. doi:10.1002/smll.200900256

5. Wang, P.; Huang, B.; Dai, Y.; Whangbo, M.-H. Phys. Chem. Chem. Phys. 2012, 14, 9813-9825. doi:10.1039/C2CP40823F

6. Zhang, X.; Chen, Y. L.; Liu, R.-S.; Tsai, D. P. Rep. Prog. Phys. 2013, 76, 046401. doi:10.1088/0034-4885/76/4/046401

7. Wang, Z.; Liu, Y.; Huang, B.; Dai, Y.; Lou, Z.; Wang, G.; Zhang, X.; Qin, X. Phys. Chem. Chem. Phys. 2014, 16, 2758-2774. doi:10.1039/C3CP53817F

8. Cushing, S. K.; Li, J.; Meng, F.; Senty, T. R.; Suri, S.; Zhi, M.; Li, M.; Bristow, A. D.; Wu, N. J. Am. Chem. Soc. 2012, 134, 15033-15041. doi:10.1021/ja305603t

9. Linic, S.; Christopher, P.; Ingram, D. B. Nat. Mater. 2011, 10, 911-921. doi:10.1038/nmat3151

10. Shin, D. O.; Jeong, J.-R.; Han, T. H.; Koo, C. M.; Park, H.-J.; Lim, Y. T.; Kim, S. O. J. Mater. Chem. 2010, 20, 7241-7247. doi:10.1039/C0JM01319F

11. Moores, A.; Goettmann, F. New J. Chem. 2006, 30, 1121-1132. doi:10.1039/B604038C

12. Wang, X.; Zhu, M.; Sun, Y.; Fu, W.; Gu, Q.; Zhang, C.; Zhang, Y.; Dai, Y.; Sun, Y. Part. Part. Syst. Charact. 2016, 33, 140-149. doi:10.1002/ppsc.201500139

13. Sarina, S.; Waclawik, E. R.; Zhu, H. Green Chem. 2013, 15, 1814-1833. doi:10.1039/C3GC40450A

14. Wang, C.; Astruc, D. Chem. Soc. Rev. 2014, 43, 7188-7216. doi:10.1039/C4CS00145A

15. Kelly, K. L.; Coronado, E.; Zhao, L. L.; Schatz, G. C. J. Phys. Chem. B 2003, 107, 668-677. doi:10.1021/jp026731y

16. Clavero, C. Nat. Photonics 2014, 8, 95-103. doi:10.1038/nphoton.2013.238

17. Galian, R. E.; Pérez-Prieto, J. Energy Environ. Sci. 2010, 3 , 1488-1498. doi:10.1039/COEE00003E

18. Barnes, W. L.; Dereux, A.; Ebbesen, T. W. Nature 2003, 424, 824-830. doi:10.1038/nature01937

19. Chen, Y.; Xin, X.; Zhang, N.; Xu, Y.-J. Part. Part. Syst. Charact. 2017, 34, 1600357. doi:10.1002/ppsc.201600357

20. Stahl, S. S. Science 2005, 309, 1824-1826. doi:10.1126/science.1114666

21. Boltasseva, A.; Atwater, H. A. Science 2011, 331, 290-291. doi:10.1126/science.1198258

22. Choi, M.; Shin, K.-H.; Jang, J. J. Colloid Interface Sci. 2010, 341, 83-87. doi:10.1016/j.jcis.2009.09.037

23. Tada, H.; Kiyonaga, T.; Naya, S.-i. Chem. Soc. Rev. 2009, 38, 1849-1858. doi:10.1039/B822385H

24. Xie, Y.; Kum, J.; Zhao, X.; Cho, S. O. Semicond. Sci. Technol. 2011, 26, 085037. doi:10.1088/0268-1242/26/8/085037

25. Mohapatra, S. K.; Kondamudi, N.; Banerjee, S.; Misra, M. Langmuir 2008, 24, 11276-11281. doi:10.1021/la801253f
26. Kwak, B.-S.; Chae, J.-H.; Kim, J.-Y.; Kang, M.-S Bull. Korean Chem. Soc. 2009, 30, 1047-1053. doi:10.5012/bkcs.2009.30.5.1047

27. Garcia, M. A. J. Phys. D: Appl. Phys. 2011, 44, 283001. doi:10.1088/0022-3727/44/28/283001

28. Kale, M. J.; Avanesian, T.; Christopher, P. ACS Catal. 2014, 4, 116-128. doi:10.1021/cs400993w

29. Molina, R. A.; Weinmann, D.; Jalabert, R. A. Phys. Rev. B 2002, 65, 155427. doi:10.1103/PhysRevB.65.155427

30. White, T. P.; Catchpole, K. R. Appl. Phys. Lett. 2012, 101, 073905. doi:10.1063/1.4746425

31. Leong, K. H.; Sim, L. C.; Saravanan, P.; Ibrahim, S. Light Driven Nanomaterials for Removal of Agricultural Toxins. In Nanoscience in Food and Agriculture 3; Ranjan, S.; Dasgupta, N.; Lichtfouse, E., Eds.; Sustainable Agriculture Reviews, Vol. 23; Springer: Berlin, Germany, 2016; pp 225-242. doi:10.1007/978-3-319-48009-1_9

32. Bumajdad, A.; Madkour, M. Phys. Chem. Chem. Phys. 2014, 16, 7146-7158. doi:10.1039/C3CP54411G

33. Qu, Y.; Duan, X. Chem. Soc. Rev. 2013, 42, 2568-2580. doi:10.1039/C2CS35355E

34. Liu, S.; Han, C.; Tang, Z.-R.; Xu, Y.-J. Mater. Horiz. 2016, 3, 270-282. doi:10.1039/C6MH00063K

35. Wang, H.; Zhang, L.; Chen, Z.; Hu, J.; Li, S.; Wang, Z.; Liu, J.; Wang, X. Chem. Soc. Rev. 2014, 43, 5234-5244. doi:10.1039/C4CS00126E

36. Ong, W.-J.; Tan, L.-L.; Chai, S.-P.; Yong, S.-T.; Mohamed, A.-R. Nanoscale 2014, 6, 1946-2008. doi:10.1039/C3NR04655A

37. Wang, J.; Tang, L.; Zeng, G.; Liu, Y.; Zhou, Y.; Deng, Y.; Wang, J.; Peng, B. ACS Sustainable Chem. Eng. 2017, 5, 1062-1072. doi:10.1021/acssuschemeng.6b02351

38. Rajender, G.; Choudhury, B.; Giri, P. K. Nanotechnology 2017, 28, 395703. doi:10.1088/1361-6528/aa810a

39. Ong, W.-J.; Putri, L. K.; Tan, L.-L.; Chai, S.-P.; Yong, S.-T. Appl. Catal., B: Environ. 2016, 180, 530-543. doi:10.1016/j.apcatb.2015.06.053

40. Ong, W.-J.; Putri, L. K.; Tan, Y.-C.; Tan, L.-L.; Li, N.; Ng, Y. H.; Wen, X.; Chai, S.-P. Nano Res. 2017, 10, 1673-1696. doi:10.1007/s12274-016-1391-4

41. Zeng, D.; Xu, W.; Ong, W.-J.; Xu, J.; Ren, H.; Chen, Y.; Zheng, H.; Peng, D.-L. Appl. Catal., B: Environ. 2018, 221, 47-55. doi:10.1016/j.apcatb.2017.08.041

42. Zeng, D.; Ong, W.-J.; Zheng, H.; Wu, M.; Chen, Y.; Peng, D.-L.; Han, M.-Y. J. Mater. Chem. A 2017, 5, 16171-16178. doi:10.1039/C7TA04816E

43. Ong, W.-J.; Tan, L.-L.; Ng, Y. H.; Yong, S.-T.; Chai, S.-P. Chem. Rev. 2016, 116, 7159-7329. doi:10.1021/acs.chemrev.6b00075

44. Ong, W.-J. Front. Mater. 2017, 4, 11. doi:10.3389/fmats.2017.00011

45. Yu, S.; Wilson, A. J.; Kumari, G.; Zhang, X.; Jain, P. K. ACS Energy Lett. 2017, 2, 2058-2070. doi:10.1021/acsenergylett.7b00640

46. Rahmanian, E.; Malekfar, R.; Pumera, M. Chem. - Eur. J. 2018, 24 , 18-31. doi:10.1002/chem.201703434

47. Zeng, D.; Xiao, L.; Ong, W.-J.; Wu, P.; Zheng, H.; Chen, Y.; Peng, D.-L. ChemSusChem 2017, 10, 4624-4631. doi:10.1002/cssc.201701345

48. Zhang, Z.; Zheng, T.; Li, X.; Xu, J.; Zeng, H. Part. Part. Syst. Charact. 2016, 33, 457-472. doi:10.1002/ppsc.201500243

49. Chen, X.; Li, N.; Kong, Z.; Ong, W.-J.; Zhao, X. Mater. Horiz. 2018, 5 , 9-27. doi:10.1039/C7MH00557A 
50. Leong, K. H.; Chu, H. Y.; Ibrahim, S.; Saravanan, P. Beilstein J. Nanotechnol. 2015, 6, 428. doi:10.3762/bjnano.6.43

51. Leong, K. H.; Gan, B. L.; Ibrahim, S.; Saravanan, P. Appl. Surf. Sci. 2014, 319, 128-135. doi:10.1016/j.apsusc.2014.06.153

52. Rather, R. A.; Singh, S.; Pal, B. Sol. Energy Mater. Sol. Cells 2017, 160, 463-469. doi:10.1016/j.solmat.2016.11.017

53. Singh, J.; Satpati, B.; Mohapatra, S. Plasmonics 2017, 12, 877-888. doi:10.1007/s11468-016-0339-6

54. Stucchi, M.; Bianchi, C. L.; Argirusis, C.; Pifferi, V.; Neppolian, B.; Cerrato, G.; Boffito, D. C. Ultrason. Sonochem. 2018, 40, 282-288. doi:10.1016/j.ultsonch.2017.07.016

55. Suwanchawalit, C.; Wongnawa, S.; Sriprang, P.; Meanha, P. Ceram. Int. 2012, 38, 5201-5207. doi:10.1016/j.ceramint.2012.03.027

56. Zhao, C.; Zhu, D.-c.; Cheng, X.-y.; Cao, S.-x. Front. Mater. Sci. 2017, 11, 241-249. doi:10.1007/s11706-017-0386-8

57. Chen, Z.; Fang, L.; Dong, W.; Zheng, F.; Shen, M.; Wang, J. J. Mater. Chem. A 2014, 2, 824-832. doi:10.1039/C3TA13985A

58. Eom, H.; Jung, J.-Y.; Shin, Y.; Kim, S.; Choi, J.-H.; Lee, E.; Jeong, J.-H.; Park, I. Nanoscale 2014, 6, 226-234. doi:10.1039/C3NR04388F

59. Xia, H.; Wu, S.; Bi, J.; Zhang, S. Nanotechnology 2017, 28, 465604. doi:10.1088/1361-6528/aa8d94

60. Sung-Suh, H. M.; Choi, J. R.; Hah, H. J.; Koo, S. M.; Bae, Y. C. J. J. Photochem. Photobiol., A 2004, 163, 37-44. doi:10.1016/S1010-6030(03)00428-3

61. Chen, D.; Chen, Q.; Ge, L.; Yin, L.; Fan, B.; Wang, H.; Lu, H.; Xu, H.; Zhang, R.; Shao, G. Appl. Surf. Sci. 2013, 284, 921-929. doi:10.1016/j.apsusc.2013.08.051

62. Kumar, S.; Kumar, A.; Bahuguna, A.; Sharma, V.; Krishnan, V. Beilstein J. Nanotechnol. 2017, 8, 1571-1600. doi:10.3762/bjnano.8.159

63. Xiang, Q.; Yu, J.; Cheng, B.; Ong, H. C. Chem. - Asian J. 2010, 5, 1466-1474. doi:10.1002/asia.200900695

64. Bian, Z.; Tachikawa, T.; Zhang, P.; Fujitsuka, M.; Majima, T. J. Am. Chem. Soc. 2014, 136, 458-465. doi:10.1021/ja410994f

65. Zhu, X.; Jin, C.; Li, X.-S.; Liu, J.-L.; Sun, Z.-G.; Shi, C.; Li, X.; Zhu, A.-M. ACS Catal. 2017, 7, 6514-6524. doi:10.1021/acscatal.7b01658

66. Tahir, B.; Tahir, M.; Amin, N. A. S. Clean Technol. Environ. Policy 2016, 18, 2147-2160. doi:10.1007/s10098-016-1181-4

67. Ding, D.; Liu, K.; He, S.; Gao, C.; Yin, Y. Nano Lett. 2014, 14, 6731-6736. doi:10.1021/nl503585m

68. Priebe, J. B.; Radnik, J.; Lennox, A. J.; Pohl, M.-M.; Karnahl, M.; Hollmann, D.; Grabow, K.; Bentrup, U.; Junge, H.; Beller, M.; Brückner, A. ACS Catal. 2015, 5, 2137-2148. doi:10.1021/cs5018375

69. Bumajdad, A.; Madkour, M.; Abdel-Moneam, Y.; El-Kemary, M. J. Mater. Sci. 2014, 49, 1743-1754. doi:10.1007/s10853-013-7861-0

70. Puga, A. V.; Forneli, A.; García, H.; Corma, A. Adv. Funct. Mater. 2014, 24, 241-248. doi:10.1002/adfm.201301907

71. Mehta, A.; Sharma, M.; Kumar, A.; Basu, S. Gold Bull. 2017, 50, 33-41. doi:10.1007/s13404-016-0191-7

72. Nalbandian, M. J.; Greenstein, K. E.; Shuai, D.; Zhang, M.; Choa, Y.-H.; Parkin, G. F.; Myung, N. V.; Cwiertny, D. M. Environ. Sci. Technol. 2015, 49, 1654-1663. doi:10.1021/es502963t

73. Liu, E.; Fan, J.; Hu, X.; Hu, Y.; Li, H.; Tang, C.; Sun, L.; Wan, J. J. Mater. Sci. 2015, 50, 2298-2305. doi:10.1007/s10853-014-8793-z

74. Khan, M. A.; Sinatra, L.; Oufi, M.; Bakr, O. M.; Idriss, H. Catal. Lett. 2017, 147, 811-820. doi:10.1007/s10562-017-1998-4

75. Seifvand, N.; Kowsari, E. Ind. Eng. Chem. Res. 2016, 55, 10533-10543. doi:10.1021/acs.iecr.6b02783
76. Kalarivalappil, V.; Divya, C. M.; Wunderlich, W.; Pillai, S. C.; Hinder, S. J.; Nageri, M.; Kumar, V.; Vijayan, B. K. Catal. Lett. 2016, 146, 474-482. doi:10.1007/s10562-015-1663-8

77. Li, N.; Liu, M.; Yang, B.; Shu, W.; Shen, Q.; Liu, M.; Zhou, J. J. Phys. Chem. C 2017, 121, 2923-2932. doi:10.1021/acs.jpcc.6b12683

78. Fujimoto, T. M.; Ponczek, M.; Rochetto, U. L.; Landers, R.; Tomaz, E. Environ. Sci. Pollut. Res. 2017, 24, 6390-6396. doi:10.1007/s11356-016-6494-7

79. Wu, J.; Lu, S.; Ge, D.; Zhang, L.; Chen, W.; Gu, H. RSC Adv. 2016, 6, 67502-67508. doi:10.1039/C6RA10408H

80. Yilmaz, P.; Lacerda, A. M.; Larrosa, I.; Dunn, S. Electrochim. Acta 2017, 231, 641-649. doi:10.1016/j.electacta.2017.02.035

81. Ong, W.-J.; Tan, L.-L.; Chai, S.-P.; Yong, S.-T. Dalton Trans. 2015, 44, 1249-1257. doi:10.1039/c4dt02940b

82. Zhu, Z.; Wu, R.-J. J. Taiwan Inst. Chem. Eng. 2015, 50, 276-281. doi:10.1016/j.jtice.2014.12.022

83. Shiraishi, Y.; Sakamoto, H.; Fujiwara, K.; Ichikawa, S.; Hirai, T. ACS Catal. 2014, 4, 2418-2425. doi:10.1021/cs500447n

84. Wei, P.; Liu, J.; Li, Z. Ceram. Int. 2013, 39, 5387-5391. doi:10.1016/j.ceramint.2012.12.045

85. Wang, W.-K.; Chen, J.-J.; Li, W.-W.; Pei, D.-N.; Zhang, X.; Yu, H.-Q. ACS Appl. Mater. Interfaces 2015, 7, 20349-20359. doi:10.1021/acsami.5b06161

86. Lv, J.; Gao, H.; Wang, H.; Lu, X.; Xu, G.; Wang, D.; Chen, Z.; Zhang, X.; Zheng, Z.; Wu, Y. Appl. Surf. Sci. 2015, 351, 225-231. doi:10.1016/j.apsusc.2015.05.139

87. Putri, L. K.; Ong, W.-J.; Chang, W. S.; Chai, S.-P. Catal. Sci. Technol. 2016, 6, 744-754. doi:10.1039/C5CY00767D

88. Ingram, D. B.; Linic, S. J. Am. Chem. Soc. 2011, 133, 5202-5205. doi:10.1021/ja200086g

89. Thomann, I.; Pinaud, B. A.; Chen, Z.; Clemens, B. M.; Jaramillo, T. F.; Brongersma, M. L. Nano Lett. 2011, 11, 3440-3446. doi:10.1021/nl201908s

90. Torimoto, T.; Horibe, H.; Kameyama, T.; Okazaki, K.-i.; Ikeda, S.; Matsumura, M.; Ishikawa, A.; Ishihara, H. J. Phys. Chem. Lett. 2011, 2, 2057-2062. doi:10.1021/jz2009049

91. Chai, S. Y.; Kim, Y. J.; Jung, M. H.; Chakraborty, A. K.; Jung, D.; Lee, W. I. J. Catal. 2009, 262, 144-149. doi:10.1016/j.jcat.2008.12.020

92. Wang, C.; Shao, C.; Liu, Y.; Zhang, L. Scr. Mater. 2008, 59, 332-335. doi:10.1016/j.scriptamat.2008.03.038

93. Sun, S.; Wang, W.; Zhang, L.; Shang, M.; Wang, L. Catal. Commun. 2009, 11, 290-293. doi:10.1016/j.catcom.2009.09.026

94. Christopher, P.; Xin, H.; Linic, S. Nat. Chem. 2011, 3, 467-472. doi:10.1038/nchem.1032

95. Wu, T.; Liu, S.; Luo, Y.; Lu, W.; Wang, L.; Sun, X. Nanoscale 2011, 3 , 2142-2144. doi:10.1039/C1NR10128E

96. Chen, X.; Zhu, H.-Y.; Zhao, J.-C.; Zheng, Z.-F.; Gao, X.-P. Angew. Chem., Int. Ed. Engl. 2008, 47, 5353. doi:10.1002/anie.200800602

97. Langhammer, C.; Yuan, Z.; Zorić, I.; Kasemo, B. Nano Lett. 2006, 6, 833-838. doi:10.1021/n1060219x

98. Langhammer, C.; Kasemo, B.; Zorić, I. J. Chem. Phys. 2007, 126, 194702. doi:10.1063/1.2734550

99. Tabor, C.; Murali, R.; Mahmoud, M.; El-Sayed, M. A. J. Phys. Chem. A 2009, 113, 1946-1953. doi:10.1021/jp807904s 100.Zhang, Q.; Tan, Y. N.; Xie, J.; Lee, J. Y. Plasmonics 2009, 4, 9-22. doi:10.1007/s11468-008-9067-x 
101.Xu, H.; Li, H.; Xia, J.; Yin, S.; Luo, Z.; Liu, L.; Xu, L. ACS Appl. Mater. Interfaces 2011, 3, 22-29. doi:10.1021/am100781n 102.Wang, P.; Huang, B.; Zhang, X.; Qin, X.; Jin, H.; Dai, Y.; Wang, Z.; Wei, J.; Zhan, J.; Wang, S.; Wang, J.; Whangbo, M.-H. Chem. - Eur. J. 2009, 15, 1821-1824. doi:10.1002/chem.200802327 103.Purbia, R.; Paria, S. Dalton Trans. 2017, 46, 890-898. doi:10.1039/C6DT03723B

104.Shuang, S.; Lv, R.; Xie, Z.; Zhang, Z. Sci. Rep. 2016, 6, No. 26670. doi:10.1038/srep26670

105.Sá, J.; Tagliabue, G.; Friedli, P.; Szlachetko, J.; Rittmann-Frank, M. H.; Santomauro, F. G.; Milne, C. J.; Sigg, H. Energy Environ. Sci. 2013, 6, 3584-3588. doi:10.1039/C3EE42731E

106.Amidani, L.; Naldoni, A.; Malvestuto, M.; Marelli, M.; Glatzel, P.; Dal Santo, V.; Boscherini, F. Angew. Chem. 2015, 127, 5503-5506. doi:10.1002/ange.201412030

107.Furube, A.; Du, L.; Hara, K.; Katoh, R.; Tachiya, M. J. Am. Chem. Soc. 2007, 129, 14852-14853. doi:10.1021/ja076134v 108.Chen, H. M.; Chen, C. K.; Chen, C.-J.; Cheng, L.-C.; Wu, P. C.; Cheng, B. H.; Ho, Y. Z.; Tseng, M. L.; Hsu, Y.-Y.; Chan, T.-S.; Lee, J.-F.; Liu, R.-S.; Tsai, D. P. ACS Nano 2012, 6, 7362-7372. doi:10.1021/nn3024877

109.Wei, Z.; Rosa, L.; Wang, K.; Endo, M.; Juodkazis, S.; Ohtani, B.; Kowalska, E. Appl. Catal., B 2017, 206, 393-405. doi:10.1016/j.apcatb.2017.01.043

110.Zhang, L.; Herrmann, L. O.; Baumberg, J. J. Sci. Rep. 2015, 5, No. 16660 . doi: $10.1038 /$ srep16660

111.Cui, J.; Li, Y.; Liu, L.; Chen, L.; Xu, J.; Ma, J.; Fang, G.; Zhu, E.; Wu, H.; Zhao, L.; Wang, L.; Huang, Y. Nano Lett. 2015, 15, 6295-6301. doi:10.1021/acs.nanolett.5b00950

112.Yang, W.; Xiong, Y.; Zou, L.; Zou, Z.; Li, D.; Mi, Q.; Wang, Y.; Yang, H. Nanoscale Res. Lett. 2016, 11, 283. doi:10.1186/s11671-016-1492-8

113.Ohno, T.; Masaki, Y.; Hirayama, S.; Matsumura, M. J. Catal. 2001, 204, 163-168. doi:10.1006/jcat.2001.3384

114.Nakamura, R.; Nakato, Y. J. Am. Chem. Soc. 2004, 126, 1290-1298. doi:10.1021/ja0388764

115. Nosaka, Y.; Nosaka, Y. A. Chem. Rev. 2017, 117, 11302-11336. doi:10.1021/acs.chemrev.7b00161

116. Diesen, V.; Jonsson, M. J. Phys. Chem. C 2014, 118, 10083-10087. doi:10.1021/jp500315u

117. Hirakawa, T.; Koga, C.; Negishi, N.; Takeuchi, K.; Matsuzawa, S. Appl. Catal., B 2009, 87, 46-55. doi:10.1016/j.apcatb.2008.08.027

118.Sahel, K.; Elsellami, L.; Mirali, I.; Dappozze, F.; Bouhent, M.; Guillard, C. Appl. Catal., B 2016, 188, 106-112. doi:10.1016/j.apcatb.2015.12.044

119.Wu, T.; Liu, G.; Zhao, J.; Hidaka, H.; Serpone, N. J. Phys. Chem. B 1999, 103, 4862-4867. doi:10.1021/jp9846678

120.Chen, C.; Lei, P.; Ji, H.; Ma, W.; Zhao, J.; Hidaka, H.; Serpone, N. Environ. Sci. Technol. 2004, 38, 329-337. doi:10.1021/es034384f

121.Lippert, A. R.; Van De Bittner, G. C.; Chang, C. J. Acc. Chem. Res. 2011, 44, 793-804. doi:10.1021/ar200126t

122.Fu, X.; Tang, Y.; Dickinson, B. C.; Chang, C. J.; Chang, Z. Biochem. Biophys. Res. Commun. 2015, 458, 896-900. doi:10.1016/j.bbrc.2015.02.055

123.Wang, D.; Zhao, L.; Guo, L.-H.; Zhang, H. Anal. Chem. 2014, 86, 10535-10539. doi:10.1021/ac503213m

124.Nakamura, K.; Ishiyama, K.; Ikai, H.; Kanno, T.; Sasaki, K.; Niwano, Y.; Kohno, M. J. Clin. Biochem. Nutr. 2011, 49, 87-95. doi:10.3164/jcbn.10-125
125. Tachikawa, T.; Majima, T. J. Fluoresc. 2007, 17, 727-738. doi:10.1007/s10895-007-0181-5

126. Tachikawa, T.; Majima, T. Chem. Soc. Rev. 2010, 39, 4802-4819. doi:10.1039/B919698F

127. Yagi, M.; Takemoto, S.; Sasase, R. Chem. Lett. 2004, 33, 152-153. doi:10.1246/cl.2004.152

128. Murakami, Y.; Endo, K.; Ohta, I.; Nosaka, A. Y.; Nosaka, Y. J. Phys. Chem. C 2007, 111, 11339-11346. doi:10.1021/jp0722049

129. Sawada, T.; Yoshino, F.; Kimoto, K.; Takahashi, Y.; Shibata, T.; Hamada, N.; Sawada, T.; Toyoda, M.; Lee, M.-C. J. Dent. Res. 2010, 89, 848-853. doi:10.1177/0022034510370806

130. Naito, K.; Tachikawa, T.; Fujitsuka, M.; Majima, T. J. Phys. Chem. C 2008, 112, 1048-1059. doi:10.1021/jp076335।

131.Kim, W.; Tachikawa, T.; Moon, G.-h.; Majima, T.; Choi, W. Angew. Chem., Int. Ed. 2014, 53, 14036-14041. doi:10.1002/anie.201406625

132. Hawkins, C. L.; Davies, M. J. Biochim. Biophys. Acta, Gen. Subj. 2014, 1840, 708-721. doi:10.1016/j.bbagen.2013.03.034

133.Zhao, H.; Joseph, J.; Zhang, H.; Karoui, H.; Kalyanaraman, B. Free Radical Biol. Med. 2001, 31, 599-606. doi:10.1016/S0891-5849(01)00619-0

134.Saita, M.; Kobatashi, K.; Yoshino, F.; Hase, H.; Nonami, T.; Kimoto, K.; Lee, M.-C.-i. Dent. Mater. J. 2012, 31, 458-464. doi:10.4012/dmj.2011-192

135.Zhou, P.; Yu, J.; Jaroniec, M. Adv. Mater. 2014, 26, 4920-4935. doi:10.1002/adma.201400288

136. Kittel, C. Introduction to Solid State Physics, 5th ed.; John Wiley \& Sons Inc.: New York, NY, U.S.A., 1976.

137.Wu, X.; Yin, S.; Dong, Q.; Liu, B.; Wang, Y.; Sekino, T.; Lee, S. W.; Sato, T. Sci. Rep. 2013, 3, No. 2918. doi:10.1038/srep02918

138. Manthiram, K.; Alivisatos, A. P. J. Am. Chem. Soc. 2012, 134, 3995-3998. doi:10.1021/ja211363w

139.Zhao, Y.; Burda, C. Energy Environ. Sci. 2012, 5, 5564-5576. doi:10.1039/C1EE02734D

140.Naik, G. V.; Shalaev, V. M.; Boltasseva, A. Adv. Mater. 2013, 25 , 3264-3294. doi:10.1002/adma.201205076

141.Zhou, D.; Liu, D.; Xu, W.; Yin, Z.; Chen, X.; Zhou, P.; Cui, S.; Chen, Z.; Song, H. ACS Nano 2016, 10, 5169-5179. doi:10.1021/acsnano.6b00649

142.Kriegel, I.; Jiang, C.; Rodríguez-Fernandez, J.; Schaller, R. D.; Talapin, D. V.; Da Como, E.; Feldmann, J. J. Am. Chem. Soc. 2012, 134, 1583-1590. doi:10.1021/ja207798q

143.Dorfs, D.; Härtling, T.; Miszta, K.; Bigall, N. C.; Kim, M. R.; Genovese, A.; Falqui, A.; Povia, M.; Manna, L. J. Am. Chem. Soc. 2011, 133, 11175-11180. doi:10.1021/ja2016284

144. Mendelsberg, R. J.; Lim, S. H. N.; Zhu, Y. K.; Wallig, J.; Milliron, D. J.; Anders, A. J. Phys. D: Appl. Phys. 2011, 44, 232003. doi:10.1088/0022-3727/44/23/232003

145.Zhang, Z.; Huang, J.; Fang, Y.; Zhang, M.; Liu, K.; Dong, B. Adv. Mater. 2017, 29, 1606688. doi:10.1002/adma.201606688

146.Li, J.; Li, W.; Li, X.; Li, Y.; Bai, H.; Li, M.; Xi, G. RSC Adv. 2017, 7, 23846-23850. doi:10.1039/C7RA03389C

147.Naik, G. V.; Schroeder, J. L.; Ni, X.; Kildishev, A. V.; Sands, T. D.; Boltasseva, A. Opt. Mater. Express 2012, 2, 478-489. doi:10.1364/OME.2.000478

148. Guler, U.; Kildishev, A. V.; Boltasseva, A.; Shalaev, V. M. Faraday Discuss. 2015, 178, 71-86. doi:10.1039/C4FD00208C

149. Van Hooijdonk, E.; Vandenbem, C.; Berthier, S.; Vigneron, J. P. Opt. Express 2012, 20, 22001-22011. doi:10.1364/OE.20.022001 
150.Spinner, M.; Kovalev, A.; Gorb, S. N.; Westhoff, G. Sci. Rep. 2013, 3, 1846. doi:10.1038/srep01846

151.Yan, R.; Chen, M.; Zhou, H.; Liu, T.; Tang, X.; Zhang, K.; Zhu, H.; Ye, J.; Zhang, D.; Fan, T. Sci. Rep. 2016, 6, 20001. doi:10.1038/srep20001

152.Chhabra, R.; Sharma, J.; Wang, H. N.; Zou, S. L.; Lin, S.; Yan, H.; Lindsay, S.; Liu, Y. Nanotechnology 2009, 20, 485201. doi:10.1088/0957-4484/20/48/485201

153. Cheng, W.; Campolongo, M. J.; Cha, J. J.; Tan, S. J.; Umbach, C. C.; Muller, D. A.; Luo, D. Nat. Mater. 2009, 8, 519-525. doi:10.1038/NMAT2440

154.Capehart, S. L.; Coyle, M. P.; Glasgow, J. E.; Francis, M. B. J. Am. Chem. Soc. 2013, 135, 3011-3016. doi:10.1021/ja3078472

155.Wang, D.; Capehart, S. L.; Pal, S.; Liu, M.; Zhang, L.; Schuck, P. J.; Liu, Y.; Yan, H.; Francis, M. B.; De Yoreo, J. J. ACS Nano 2014, 8, 7896-7904. doi:10.1021/nn5015819

156.Akhtar, M. S.; Panwar, J.; Yun, Y.-S. ACS Sustainable Chem. Eng. 2013, 1, 591-602. doi:10.1021/sc300118u

157.Devi, T. B.; Ahmaruzzaman, M. Environ. Sci. Pollut. Res. 2016, 23 , 17702-17714. doi:10.1007/s11356-016-6945-1

158.Huang, J.; Li, Q.; Sun, D.; Lu, Y.; Su, Y.; Yang, X.; Wang, H.; Wang, Y.; Shao, W.; He, N.; Hong, J.; Chen, C. Nanotechnology 2007, 18, 105104. doi:10.1088/0957-4484/18/10/105104

159. Joerger, R.; Klaus, T.; Granqvist, C. G. Adv. Mater. 2000, 12, 407-409. doi:10.1002/(SICI)1521-4095(200003)12:6<407::AID-ADMA407>3.0. $\mathrm{CO} ; 2-\mathrm{O}$

160.Bhainsa, K. C.; D'souza, S. F. Colloids Surf., B 2006, 47, 160-164. doi:10.1016/j.colsurfb.2005.11.026

161.Gardea-Torresdey, J. L.; Parsons, J. G.; Gomez, E.; Peralta-Videa, J.; Troiani, H. E.; Santiago, P.; Yacaman, M. J. Nano Lett. 2002, 2, 397-401. doi:10.1021/nl015673+

162.Palanco, M. E.; Mogensen, K. B.; Gühlke, M.; Heiner, Z.; Kneipp, J.; Kneipp, K. Beilstein J. Nanotechnol. 2016, 7, 834-840. doi:10.3762/bjnano.7.75

163.Shankar, S. S.; Rai, A.; Ahmad, A.; Sastry, M. J. Colloid Interface Sci. 2004, 275, 496-502. doi:10.1016/j.jcis.2004.03.003

164.Gao, S.; Jia, X.; Yang, S.; Li, Z.; Jiang, K. J. Solid State Chem. 2011, 184, 764-769. doi:10.1016/j.jssc.2011.01.025

165.Patil, S. S.; Mali, M. G.; Tamboli, M. S.; Patil, D. R.; Kulkarni, M. V.; Yoon, H.; Kim, H.; Al-Deyab, S. S.; Yoon, S. S.; Kolekar, S. S.; Kale, B. B. Catal. Today 2016, 260, 126-134. doi:10.1016/j.cattod.2015.06.004

166. Christopher, P.; Xin, H.; Marimuthu, A.; Linic, S. Nat. Mater. 2012, 11, 1044-1050. doi:10.1038/NMAT3454

167.Xiao, Q.; Jaatinen, E.; Zhu, H. Chem. - Asian J. 2014, 9, 3046-3064. doi:10.1002/asia.201402310

168.Chen, X.; Zhu, H.-Y.; Zhao, J.-C.; Zheng, Z.-F.; Gao, X.-P. Angew. Chem. 2008, 120, 5433-5436. doi:10.1002/ange.200800602

169.Chen, X.; Zheng, Z.; Ke, X.; Jaatinen, E.; Xie, T.; Wang, D.; Guo, C.; Zhao, J.; Zhu, H. Green Chem. 2010, 12, 414-419. doi:10.1039/B921696K

170.Cheng, H.; Fuku, K.; Kuwahara, Y.; Mori, K.; Yamashita, H. J. Mater. Chem. A 2015, 3, 5244-5258. doi:10.1039/C4TA06484D

171.Wee, T.-L.; Schmidt, L. C.; Scaiano, J. C. J. Phys. Chem. C 2012, 116, 24373-24379. doi:10.1021/jp308956y

172.Zhu, H.; Ke, X.; Yang, X.; Sarina, S.; Liu, H. Angew. Chem. 2010, 122, 9851-9855. doi:10.1002/ange.201003908
173.Wang, C.; Nie, X.-G.; Shi, Y.; Zhou, Y.; Xu, J.-J.; Xia, X.-H.; Chen, H.-Y. ACS Nano 2017, 11, 5897-5905. doi:10.1021/acsnano.7b01637

174.Ke, X.; Sarina, S.; Zhao, J.; Zhang, X.; Chang, J.; Zhu, H. Chem. Commun. 2012, 48, 3509-3511. doi:10.1039/C2CC17977F 175. Marimuthu, A.; Zhang, J.; Linic, S. Science 2013, 339, 1590-1593. doi:10.1126/science. 1231631

\section{License and Terms}

This is an Open Access article under the terms of the Creative Commons Attribution License

(http://creativecommons.org/licenses/by/4.0), which permits unrestricted use, distribution, and reproduction in any medium, provided the original work is properly cited.

The license is subject to the Beilstein Journal of Nanotechnology terms and conditions:

(https://www.beilstein-journals.org/bjnano)

The definitive version of this article is the electronic one which can be found at: doi:10.3762/bjnano.9.59 